\title{
Information, Competition, and the Quality of Charities
}

\author{
Huseyin Yildirim Silvana \\ Krasteva \\ Duke University Texas A\&M University
}

May 16, 2015

ERID Working Paper Number 188

This paper can be downloaded without charge from the Social Science Research Network Electronic Paper Collection:

http://ssrn.com/abstract=2617490

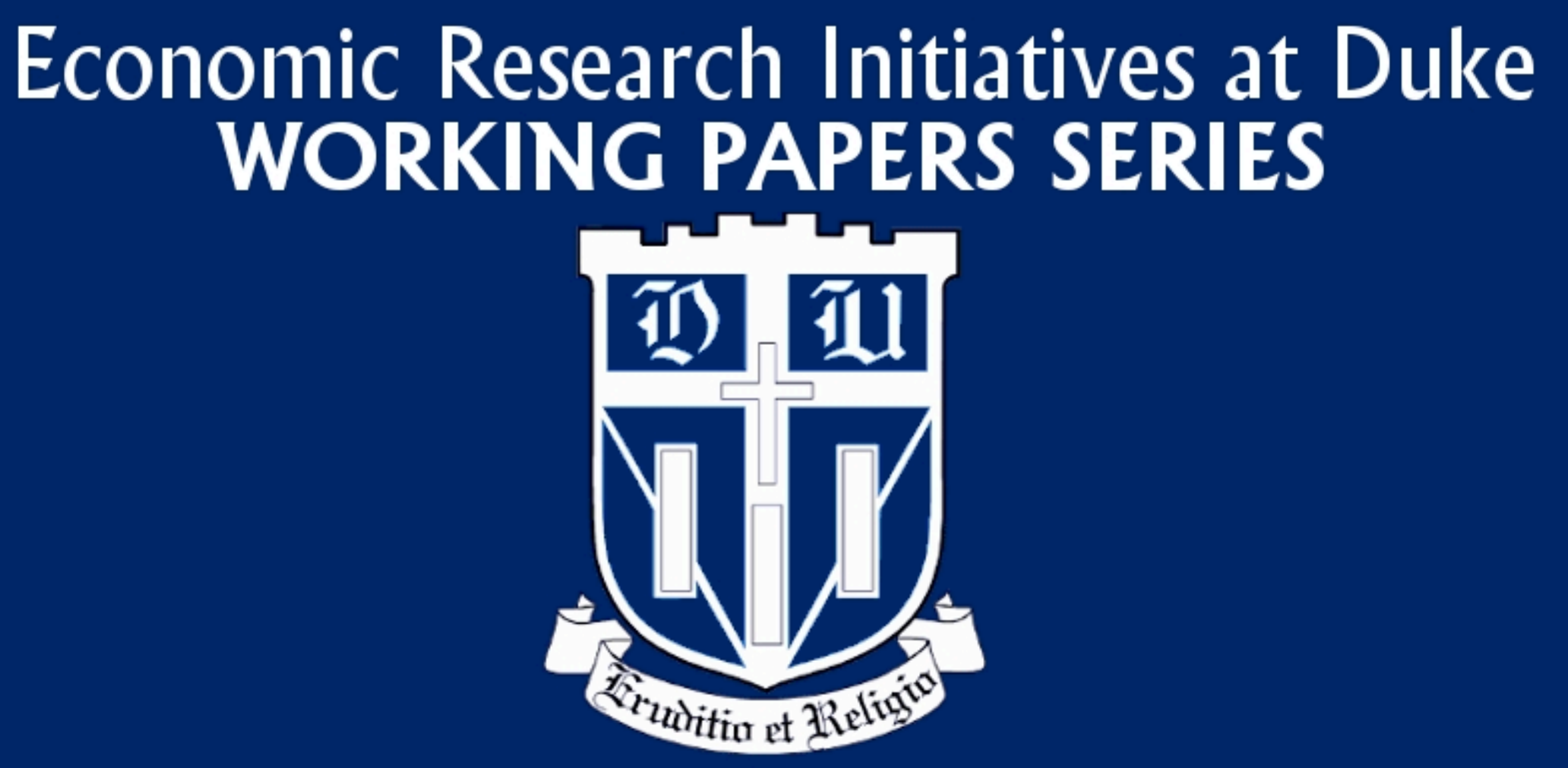




\title{
Information, Competition, and the Quality of Charities*
}

\author{
Silvana Krasteva \\ Department of Economics \\ Texas A\&M University \\ Allen 3054 \\ College Station, TX 77843 \\ E-mail: ssk8@tamu.edu
}

\author{
Huseyin Yildirim \\ Department of Economics \\ Duke University \\ Box 90097 \\ Durham, NC 27708 \\ E-mail: hy12@duke.edu
}

May 16, 2015

\begin{abstract}
We propose a model of charity competition in which informed giving alone can explain quality heterogeneity across similar charities. It is this heterogeneity that also creates the demand for information. In equilibrium, too few donors pay to be informed; but interestingly, informed giving may increase with the cost of information. This is true if the charitable market is highly competitive or if private consumption is a strong substitute to giving - both of which are supported by evidence.
\end{abstract}

Keywords: informed giving, quality of charity, competition, all-pay auctions.

JEL Classification: H00, H30, H50

\section{Introduction}

Up 30 percent from a decade ago, the number of public charities in the United States exceeded one million in 2013 (Urban Institute, 2014) 1 Charity Navigator rates the largest 8000 by identifying nine categories of activity (e.g., animals) and 34 causes (e.g., zoos and aquariums, museums, and homeless services). Its rating reveals that the quality of the charities within each cause varies significantly with about one-third failing industry standards $\sqrt{2}^{2}$ The challenge for donors is therefore not finding a cause to support but choosing

\footnotetext{
*We thank seminar participants at Duke, Texas A\&M, USC (Columbia), and UT (Austin) for comments. All remaining errors are ours.

${ }^{1}$ This figure is consistent with the fact that the Internal Revenue Service (IRS) approves more than 90 percent of all applications for a charity status (Reich et al. 2009). Unlike other nonprofits such as private foundations, public charities rely heavily on contributions from the general public, which consistently total about 1.5 percent of GDP in the U.S - \$241.3 billion in 2013.

${ }^{2}$ For details, visit www. charitynavigator.org. Significant quality variation is also reported by other major charity evaluators including BBB Wise Giving Alliance and GuideStar. Not surprisingly, it is such variation that has facilitated recent empirical investigations of charity ratings (e.g., Yoruk (forthcoming)).
} 
the charity that is most deserving. Despite the importance of information, however, giving remains largely uninformed (Hope Consulting Report, 2010) ${ }^{3}$ In this paper, we propose a model of charity competition in which informed giving alone drives the vast quality heterogeneity across similar charities and creates the endogenous demand for information in turn.

Our model contains a large pool of ex ante identical charities that may begin fundraising for a given cause by incurring a setup cost - e.g., website design, staffing, and the IRS application - and pre-committing to the quality of their programs or services $4^{4}$ The quality may reflect investments in infrastructure, planning, staff training, and program evaluation that improve charitable work. Each charity maximizes net donations to be used for its own program. Donors are assumed identical except for their information. An informed donor gives to the highest quality charity, perhaps using a rating agency, whereas an uninformed donor gives to a charity at random. The latter implies that a charity may choose to "scam" the uninformed: begin fundraising but offer minimal quality. Under free entry, the windfall profit from the uninformed is exhausted. A charity can therefore contribute to the cause only if it wins the informed donation. This incentive to win a lump-sum amount turns the charity competition into an "all-pay auction" and leads to mixing over quality choices in equilibrium.

In a symmetric equilibrium, we show that each charity mixes continuously over a positive interval of quality and has a mass point at zero. Such a strategy readily rationalizes the quality heterogeneity mentioned above and predicts a nontrivial probability of charity scams. We find that as the entry cost drops, more charities fundraise but interestingly, the increased competition (stochastically) decreases the highest quality offered and in turn lowers the expected welfare for all donors. The intuition is that charities are less willing to invest in a competition, in which they are unlikely to prevail. Moreover, we show that this negative competition effect on quality dominates the positive scale effect associated with the number of charities.

Our analysis suggests distinct and necessary roles for uninformed and informed donors

\footnotetext{
${ }^{3}$ Based on a nationwide survey of 4000 Americans with incomes over $\$ 80 \mathrm{~K}$, the 2010 Report found that while 85 percent of Americans say they care about nonprofit performance when they give, only 35 percent of donors research at least one of their donations each year; see www.hopeconsulting.us/moneyforgood. This finding parallels experimental evidence: whereas Eckel and Grossman (1996) document that individuals give generously when they are paired with recipients of preferred characteristics, Fong and Oberholzer-Gee (2011) observe that only one third of subjects are willing to pay for information about recipients.

${ }^{4}$ With often-nonrefundable donations, donors are unlikely to find promised/uncertified quality credible.
} 
in the charitable market: the former entice entry while the latter induce quality provision. This implies that the cost of information can be neither too high nor too low to guarantee significant masses of both donor types. As expected, in equilibrium too few donors pay to be informed because each ignores the quality effect of her decision on others. Interestingly, informed giving may increase with the cost of information! This is true if the charitable market is highly competitive or if giving and private consumption are strong substitutes $5_{5}^{5}$ In each case, decisions to become informed are strategic complements: the larger the size of the informed population, the more attractive information acquisition becomes.

Our theoretical framework draws upon two influential papers on all-pay auctions: Varian (1980) and Che and Gale (2003). Varian considers a price competition with informed and uninformed consumers in order to explain equilibrium price dispersion. Unlike quality, price does not affect consumers' reservation utility in his model. Che and Gale examine a research tournament where there is only one buyer, the procurer, whose innovation value is endogenous to the winner's effort and who decides informed. Siegel (2010) ably generalizes all-pay auctions with endogeneous valuations.

Our paper relates to the few studies on charity competition. ${ }^{6}$ Rose-Ackerman (1982) shows that competitive fundraising can be "excessive" despite donors' aversion to it. Castaneda et al. (2008) argue that such inefficiency may be reduced by nonprofits' ability to contract on the use of donations while Aldashev et al. (2014) observe that it can be overcome by fundraising coordination, though such coordination is often difficult in this voluntary sector. In the same vein, Bilodeau and Slivinski (1997) find that rival charities may specialize in the provision of one public good or service in order to attract donations. With over one million charities, there are nevertheless many that provide similar - if not identical - services but differ significantly in their quality of provision. In this sense, Scharf (2014) is closer to our work. Assuming an exogenous quality distribution, Scharf points out that competition can induce too much entry by low quality charities. We let quality choice be part of the competition and derive an endogenous distribution for it. Like her, we argue that increased entry into the charitable market decreases the (average) charity quality.

On the role of informed giving, our paper also relates to Vesterlund (2003), Andreoni (2006) and Krasteva and Yildirim (2013). Vesterlund shows that a large leadership gift can

\footnotetext{
${ }^{5}$ For experimental evidence of substitution, see Andreoni and Miller (2002) and Fisman et al. (2007).

${ }^{6}$ For a recent overview of the literature on charitable giving, see Andreoni and Payne (2013).
} 
signal the (fixed) quality of the charity. Andreoni extends this argument by demonstrating that all else equal, it is the most wealthy who will lead. Krasteva and Yildirim explore a private value setting in which donors are uncertain about their private valuations of the charity and thus no signaling incentive exists. In all these papers, informed giving, on average, raises more funds and is therefore encouraged. In contrast, our analysis emphasizes that some uninformed giving is also necessary for a charitable market with costly entry.

The rest of the paper is organized as follows. In the next section, we present the base model with exogenous donor information. In Section 3, we characterize the equilibrium and perform comparative statics. In Section 4, we endogenize donors' information. In the last two sections, we offer a robustness check for the charities' objective and then conclude. Proofs that do not appear in the text are relegated to the appendix.

\section{Base model}

A large number of ex ante identical charities decide whether or not to fundraise for a given cause. Refer to Figure 1 for a timeline. Fundraising involves a fixed setup cost $k>0-$ e.g., designing a website, staffing, and registering with the IRS. Before appealing to donors, charity $i$ invests in its program or service quality $q_{i} \in[0, \infty)$ that costs an additional $\left.q_{i}\right]^{7}$ The quality is observable by donors upon inspection, possibly through a rating agency, and it may reflect the investment in infrastructure, planning, and staff training, for instance. Charity $i$ maximizes its net revenues $R_{i}$ - total donation minus total cost - to be spent toward its program. If $R_{i} \leq 0$, the program is cancelled due to insufficient funds. Note that the charity is assumed to value the "quantity", $R_{i}$, but not the quality, $q_{i}$, of its service. While not entirely realistic, this assumption aids in identifying the (informed) donors as the source of quality provision. The analysis is generalized in Section 5.

On the supply side of the charitable market, there is a continuum of donors of mass $M$. Each donor picks a charity to support the cause. Donors are otherwise identical and come in two types: informed and uninformed. Informed donors, whose measure is $I$, ascertain the quality of the charities prior to giving while uninformed donors, whose measure is $U=M-I$, give randomly to one 8 Each donor has a unit wealth and possesses CES

\footnotetext{
${ }^{7}$ As previously mentioned, charitable contributions are often nonrefundable; hence, donors are unlikely to trust promised/uncertified quality. Our results are, however, robust to "partial" promises, whereby as in Siegel (2010, Section III), the charity invests a fraction of $q_{i}$ upon entry, with the commitment of investing the rest if enough funding is received.

${ }^{8}$ Whether or not donors observe the actual number of charities before giving is immaterial to our analy-
} 


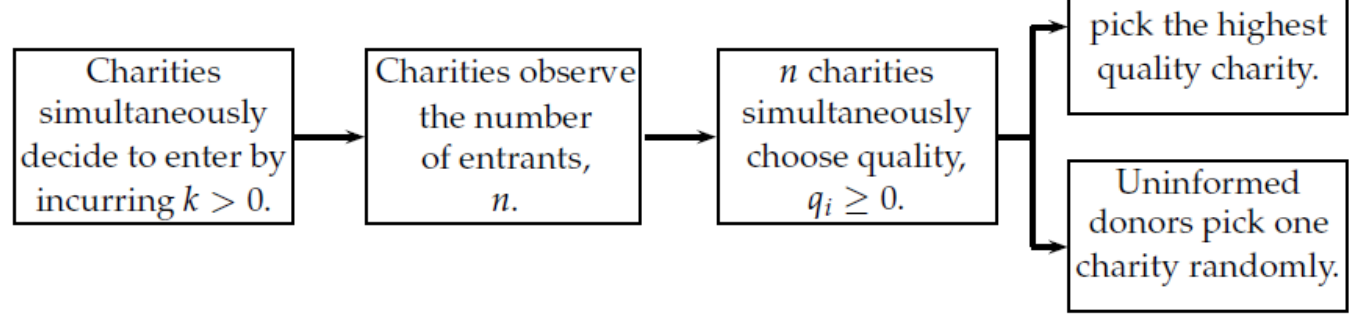

Figure 1: Timing of the game

preferences: 9

$$
u\left(x_{i}, g_{i} ; q\right)=x_{i}^{\rho}+q g_{i}^{\rho}, \rho \in(0,1)
$$

where $x_{i} \geq 0$ denotes private consumption and $g_{i} \geq 0$ denotes gift to the charity whose quality is $q$. The donor is assumed to receive no utility from giving if the charity of her choice fails to support the cause; that is, if $R_{i} \leq 0.10$ We focus on a symmetric (Nash) equilibrium with pure entry decisions.

\subsection{Discussion of the model}

Our model is designed to highlight donors' information as the unique source of quality heterogeneity. We therefore assume all charities and donors are ex ante identical except for the donors' information, which is endogenized in Section 4. Consistent with the literature, we assume "warm-glow" charities that care only about their own provision of the public good. This is not critical, however. The qualitative results hold as long as charities favor their own provision so that there is rivalry. From (1), it is evident that we also assume "warm-glow" givers (Andreoni, 1990). This is a reasonable description of charitable behavior for a continuum of donors. As argued by Glazer and Konrad (1996), suppose that $\Gamma$ is the total provision of the public good by all charities in the market. Let the public good

sis. All we need is for the informed to give to the highest quality, perhaps using a rating agency, and the uninformed to give to a random charity, perhaps to the first fundraiser that solicits.

${ }^{9}$ This way of modeling preference for quality mirrors those of Vesterlund (2003) and Andreoni's (2006). The CES form is assumed for expositional ease as the analysis readily extends to: $u\left(x_{i}, g_{i} ; q\right)=t\left(x_{i}\right)+q w\left(g_{i}\right)$ where both $t$ and $w$ are strictly increasing and strictly concave.

${ }^{10}$ Perhaps, the list of charities that help the cause such as active homeless shelters, open museums, and participating relief organizations is publicized. Our qualitative results, however, hold if donors are assumed to enjoy giving regardless. 


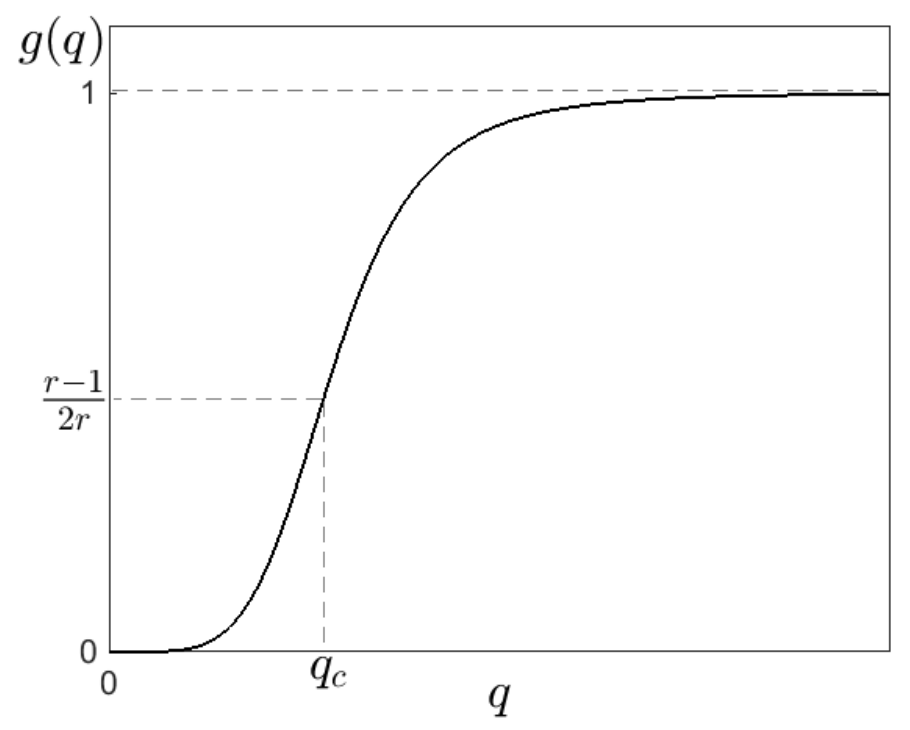

Figure 2: Optimal individual gift: $g(q)=\frac{q^{r}}{1+q^{r}}$

enter the utility in an additively separable way: $x_{i}^{\rho}+q g_{i}^{\rho}+z_{i}(\Gamma)$. Since with a continuum of donors $d \Gamma / d g_{i}=0$, the altruistic motive for giving has no effect on donors' behavior ${ }^{11}$

\section{Equilibrium characterization}

Maximizing the utility in (1) subject to the budget constraint, $x_{i}+g_{i}=1$, donor $i$ 's optimal gift for fixed quality $q$ is found to be

$$
g_{i}=g(q) \equiv \frac{q^{r}}{1+q^{r}}
$$

where $r=\frac{1}{1-\rho} \in(1, \infty)$ is the elasticity of substitution between private consumption and donation. Refer to Figure 2. It is readily verified that (a) $g(0)=g^{\prime}(0)=0$; (b) $g^{\prime}(q)>0$ for $q>0$, and (c) $g^{\prime \prime}(q)>0$ for $q<q_{c}$ and $g^{\prime \prime}(q)<0$ for $q>q_{c}$, where $q_{c}=\left(\frac{r-1}{r+1}\right)^{\frac{1}{r}}$. That is, giving is increasing in quality - at an increasing rate for its low levels and at a decreasing rate for its high levels.

Inspecting quality, an informed donor optimally gives to the highest ranked charity, denoted by $q_{\max }$. An uninformed donor, on the other hand, can only conjecture the quality

\footnotetext{
${ }^{11}$ The fact that donations are driven purely by the warm-glow motive also obtains in a large finite economy (e.g., Yildirim, 2014).
} 
of her selected charity, denoted by $q_{U}$. Using (2), the informed and uninformed gifts can be respectively written as

$$
g_{I}=g\left(q_{\max }\right) \text { and } g_{U}=g\left(q_{U}\right)
$$

Note that the behavior of informed donors turns the quality competition into an all-pay auction - e.g., Che and Gale (2003) and Siegel (2010). It is, therefore, unsurprising that there will generically be no pure strategy equilibrium in quality choice. Before stating it formally, we develop some intuition behind the equilibrium characterization.

Suppose that entry cost, $k$, is sufficiently small so that at least two charities participate in the market in equilibrium, $n^{*} \geq 2 \sqrt[12]{12}$ If charity $i$ sets quality $q$ and ranks the highest, then it captures all informed donations as well as an equal share of the uninformed, resulting in net revenues:

$$
R_{w i n}^{*}(q)=I g(q)+\frac{U}{n^{*}} g\left(q_{U}^{*}\right)-q-k
$$

If charity $i$ ranks lower, it loses informed donations but continues to receive the uninformed, generating net revenues:

$$
R_{\text {lose }}^{*}(q)=\frac{U}{n^{*}} g\left(q_{U}^{*}\right)-q-k
$$

Clearly, charity $i$ can always adopt a "scam" strategy: enter the market but choose zero quality ${ }^{13}$ Since $g(0)=0$, such a strategy can only target the uninformed. Under free entry (and ignoring integer problems), the windfall revenue from the uninformed is driven to zero:

$$
\frac{U}{n^{*}} g\left(q_{U}^{*}\right)-k=0 .
$$

Substituting for (6), (4) and (5) reduce to:

$$
R_{\text {win }}^{*}(q)=\operatorname{Ig}(q)-q \text { and } R_{\text {lose }}^{*}(q)=-q \text {, }
$$

which we depict in Figure 3. From (6) and (7), we see distinct roles for the two donor types in the charitable market: the uninformed entice charity entry while the informed engender

\footnotetext{
${ }^{12} \mathrm{~A}$ competitive charitable market is the case of most interest to us both because it is suggested by evidence and because, as we will see in the next section, a market with a single charity is not sustainable in equilibrium under endogenous information.

${ }^{13}$ We distinguish between a charity scam and failed fundraising. Although the donor receives no utility from giving in either case, in the latter, the charity invests in quality but ends up raising insufficient funds to cover its costs. This distinction is also consistent with the popular view; see http://www. consumer. ftc. gov/features/feature-0011-charity-scams
} 


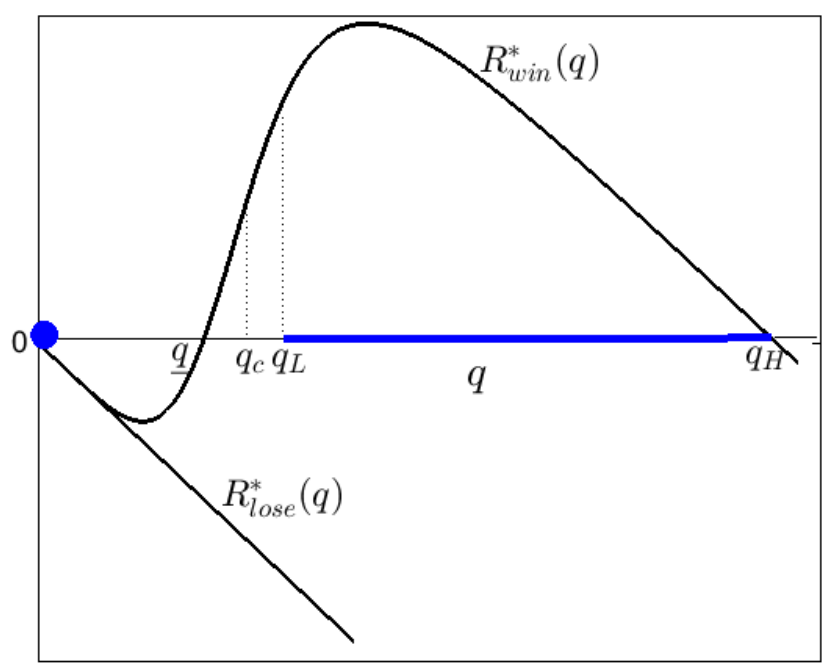

Figure 3: Winning and losing payoffs

quality competition. It is, however, possible that the total informed donation is too small to recover the cost of quality - i.e., $R_{\text {win }}^{*}(q) \leq 0$ for all $q$-in which case no incentive to enter the market exists. To rule out such trivial cases, suppose that $R_{\text {win }}^{*}(q)>0$ for some $q>0$. From (7), this implies that only the winning charity will supply the public good and that as with the informed, uninformed donors will also aim for the highest quality, whom they correctly select with probability $\frac{1}{n^{*}}$. The expected quality by the uninformed is therefore

$$
q_{U}^{*}=\frac{1}{n^{*}} E\left[\widetilde{q}_{\max }^{*}\right]
$$

where $E[$.$] denotes the expectation operator.$

To complete the characterization, let $F^{*}(q)$ denote the equilibrium distribution that represents each fundraiser's mixing over quality choices. It is determined by setting the expected net revenues to the free-entry payoff, 0 :

$$
\left(F^{*}\right)^{n^{*}-1}(q) R_{\text {win }}^{*}(q)+\left[1-\left(F^{*}\right)^{n^{*}-1}(q)\right] R_{\text {lose }}^{*}(q)=0
$$

where $\left(F^{*}\right)^{n^{*}-1}(q)$ is the probability that $q$ is the highest quality. Simplifying $(8)$, we obtain

$$
F^{*}(q)=\left(\frac{q}{I g(q)}\right)^{\frac{1}{n^{*}-1}}=\left(\frac{1}{I}\left(q+q^{1-r}\right)\right)^{\frac{1}{n^{*}-1}} .
$$

Note that $F^{*}(0)>0$ (since $\left.r>1\right)$, which suggests that there is a mass point at $q=0$. Propositions 1 and 2 collect and formalize these observations. 
Proposition 1 Consider a symmetric equilibrium with $n^{*} \geq 2$. Then,

(a) informed and uninformed gifts are respectively:

$$
g_{I}^{*}=g\left(q_{\max }^{*}\right) \text { and } g_{U}^{*}=g\left(\frac{E\left[\widetilde{q}_{\max }^{*}\right]}{n^{*}}\right) \text {. }
$$

(b) $n^{*}$ is uniquely determined by:

$$
\frac{M-I}{n^{*}} g\left(\frac{E\left[\widetilde{q}_{\max }^{*}\right]}{n^{*}}\right)-k=0
$$

(c) Each charity continuously mixes over $q \in\left[q_{L}, q_{H}\right]$ according to (9) and has a mass point at $q=0$, where $q_{L}=(r-1)^{\frac{1}{r}}$ and $q_{H}>q_{L}$ is the largest root to $R_{\text {win }}^{*}(q)=0$.

Parts (a) and (b) are as explained above. In particular, indiscriminate giving by the uninformed attracts entry until it is exhausted. This means that each charity relies on informed donations for a positive net revenue. Refer to Figure 3. For a sufficiently low quality $q \in(0, q)$, informed donations fall below the cost ${ }^{14}$ As such, the charity will either choose zero quality and grab some uninformed donations or choose a high enough quality, $q \geq \underline{q}$, and have a chance to receive informed donations, too. This tradeoff generates the mass point at zero. Standard all-pay auction arguments indicate that another (interior) mass point is not possible; otherwise, a charity could discretely increase the probability of winning by slightly improving his quality. This "race to the top" also accounts for why the lower bound of the quality distribution $q_{L}$ exceeds the intermediate break-even quality $q$ as well as why the upper bound $q_{H}$ must obtain at the highest break-even quality. The equilibrium distribution $F^{*}(q)$ is as derived in $(9)$. Intuitively, the equilibrium distribution balances the probability of winning informed donations to the cost-to-donation ratio. Since, by definition, the distribution is strictly increasing in the quality level, so is the ratio. In this sense, the cost-to-donation ratio, often utilized by leading watchdogs such as Charity Navigator appears an unreliable measure for ranking charities (Steinberg, 1991; Gneezy et al. 2014) ${ }^{15}$ We emphasize that the quality heterogeneity in our model is based solely on the donors' information - not on preference or income heterogeneity - which in turn creates demand for information; see Section 4.

\footnotetext{
${ }^{14}$ Note that $R_{\text {win }}^{* \prime}(0)=g^{\prime}(0)-1=-1$.

${ }^{15}$ Interestingly, in 2013 America's three leading charity evaluators - Charity Navigator, GuideStar, and BBB Wise Giving Alliance - wrote an open letter to the donors in a campaign to end the Overhead Myth-the false conception that financial ratios are the sole indicator of nonprofit performance (http://overheadmyth. com).
} 
Proposition 1 characterizes the equilibrium but does not guarantee its existence. Armed with $F^{*}(q),(11)$ implies that in equilibrium, $n^{*} \geq 2$ if and only if $k \leq \frac{M-I}{n^{*}} g\left(\frac{E\left[\widetilde{q}_{\max }^{*}\right]}{n^{*}}\right)$. The right-hand side of this inequality - the share of uninformed gifts - is decreasing in $n^{*}$ and single-peaked in $I$, leading us to Proposition 2.

Proposition 2 Let $k_{L} \equiv \max _{I \in[0, M]}\left[\frac{M-I}{n^{*}} g\left(\frac{E\left[\tilde{q}_{\max }^{*}\right]}{n^{*}}\right)\right]_{n^{*}=2}$ and $M>I_{c} \equiv r(r-1)^{\frac{1}{r}-1}$. For every $k<k_{L}$, there is a unique symmetric equilibrium with $n^{*} \geq 2$ if and only if $I_{L} \leq I \leq I_{H}$, where $I_{\mathcal{C}}<I_{L}$ and $I_{H}<M$.

Proposition 2 indicates that the amount of informed giving cannot be too high or too low to sustain a competitive charitable market. Given the all-pay nature of the quality choice, significant uninformed giving is needed to accommodate costly entry, while significant informed giving is also needed to encourage the costly provision of quality. The condition $M>I_{c}$ merely ensures that a positive net revenue is feasible for at least the winning charity so trivial cases of no provision are avoided; formally, $R_{w i n}^{*}(q)>0$ for some $q>0$ whenever $I>I_{c}$. In fact, $I$ must sufficiently exceed the break-even level $I_{c}$ so that at least two charities participate in the market. The uniqueness of the equilibrium follows because the uninformed gift, $g\left(\frac{E\left[\widetilde{q}_{m a x}^{*}\right]}{n^{*}}\right)$, is decreasing in the number of fundraisers, $n^{*}$, resulting in a unique $n^{*}$ for a given entry cost $k$. The source of such diminished generosity by the uninformed is a negative competition effect on quality, which we elaborate on in the next proposition. Before stating it, however, it is useful to record donors' expected payoffs. Note from (1) that a donor's indirect utility conditional on charity quality $q$ is:

$$
v(q)=\max _{g \in[0,1]}(1-g)^{\rho}+q g^{\rho}
$$

Using (2), it reduces to:

$$
v(q)=\left(1+q^{r}\right)^{\frac{1}{r}}
$$

where $v^{\prime}(q)>0$ and $v^{\prime \prime}(q)>0$. The equilibrium expected payoffs for the informed and uninformed donors are therefore

$$
v_{I}^{*}(I)=E\left[v\left(\widetilde{q}_{\max }^{*}\right)\right] \text { and } v_{U}^{*}(I)=v\left(\frac{E\left[\widetilde{q}_{\max }^{*}\right]}{n^{*}}\right) .
$$

Proposition 3 Suppose $I_{L} \leq I \leq I_{H}$. In equilibrium, as the entry cost $k$ drops

(a) the number of charities $n^{*}$ increases and goes to infinity as $k \rightarrow 0$, 
(b) the expected quality of service, $E\left[\widetilde{q}_{\max }^{*}\right]$, decreases and converges to a positive level as $k \rightarrow 0$,

(c) every donor, informed or uninformed, becomes worse off.

As entry becomes less costly, more charities enter the market. The intensified competition, however, stochastically lowers the quality of service (i.e., the maximum quality) and thus the expected donors' welfare. This is easily seen by inspecting the quality distribution in (9). Note that $F^{*}(q)$ is increasing in $n^{*}$ : charities are less willing to invest in quality in a competition (for the informed donors) that they are more likely to lose. While there is also a positive scale effect associated with the number of charities, the negative effect of competition dominates since the distribution for the maximum quality $\left(F^{*}\right)^{n^{*}}(q)$ is also increasing in $n^{*} \sqrt{16}$ In the most competitive market, the two effects balance each other out: $\left(F^{*}\right)^{n^{*}}(q) \rightarrow \frac{q}{\operatorname{Ig}(q)}$ for $q \in\left[q_{L}, q_{H}\right]$ as $n^{*} \rightarrow \infty$, leaving the expected quality of service strictly positive in the limit economy. Part (c) obtains because all donors care about the quality of service, as implied by (13). Indeed, it is clear from part (a) of Proposition 1 that, as expected, both the informed and uninformed donors turn less generous in a more competitive market with the uninformed gift approaching zero.

An important corollary to Propositions 1-3 is that the equilibrium probability that all charities are scammers remains positive even in the most competitive market. Formally,

$$
\left(F^{*}\right)^{n^{*}}(0)=\left(F^{*}\right)^{n^{*}}\left(q_{L}\right) \rightarrow \frac{I_{c}}{I} \text { as } k \rightarrow 0
$$

where $I_{c} \equiv r(r-1)^{\frac{1}{r}-1}$ as defined in Proposition $2{ }^{17}$ Building on Proposition 3, we now explore the impact of informed giving on market entry and donors' welfare, both of which will be instrumental in endogenizing information in the next section.

Proposition 4 Suppose $I_{L} \leq I \leq I_{H}$. In equilibrium,

(a) the number of charities $n^{*}$ is single-peaked in I,

(b) the expected quality of service, $E\left[\widetilde{q}_{\max }^{*}\right]$, is increasing in I,

(c) both informed or uninformed payoffs are increasing in I.

\footnotetext{
${ }^{16}(F)^{n^{*}}(q)$ would obviously be decreasing in $n^{*}$ if $F(q)$ were exogenous.

${ }^{17}$ As is evident from 99, this limit probability is positive if and only if there is a mass point at zero or $F^{*}(0)>0$, which depends on the cost of quality and donors' preferences. We have assumed a linear cost but our point is more general. If the cost of quality is $c(q)$, a mass point at zero quality exists if and only if $\frac{c(0)}{I g(0)}>0$. For instance, if $c(q)=q^{\theta}, \theta>0$, this condition reduces to $\theta \leq r$.
} 
Note from Proposition 1 that given a fixed number of charities, an increase in informed giving, $I$, raises the expected quality of service, both because it extends the quality competition - i.e., $\partial q_{H} / \partial I>0$ - and because it makes higher quality levels more likely - i.e., $\partial\left[1-F^{*}(q)\right] / \partial I>0$. Expecting a better service by the winning charity, the uninformed become more generous, which encourages further entry. Countervailing this incentive for entry, and the reason behind the non-monotonicity in part (a), is the fact that given the population size, more informed giving means less uninformed giving, which discourages entry. This non-monotonicity is illustrated in Figure 4. To understand part (b), notice that the increased informed giving can adversely affect the expected quality of service only if it entices more charities into the market. This negative competition effect must, however, be limited in equilibrium: otherwise, by Proposition 1(b), lower expected quality of service along with more charities would depress uninformed giving and lead to fewer charities in equilibrium, yielding a contradiction. The same logic reveals that the expected quality of service by the uninformed, $\frac{E\left[\widetilde{q}_{\max }^{*}\right]}{n^{*}}$, is also increasing in I. From 13 , this implies that the uninformed donor benefits from informed giving. As stated in part (c), the informed donor also benefits from informed giving by others because the indirect utility in (12) is increasing and convex in quality.

Propositions 2 and 4 stress the importance of donors' information in the charitable market. In the next section, we endogenize it and examine welfare consequences.

\section{Endogenous information}

Suppose that at the outset no donor is informed but each can get informed by paying a fixed (utility) cost $c>0.1^{18}$ This cost reflects time and energy spent in processing charities' programs and/or their watchdog ratings. The value of being informed is simply the difference between the expected informed and uninformed payoffs recorded in (13). Formally, given the mass of informed donors, $I$, the value of being informed for a representative donor is

$$
\begin{aligned}
\Delta(I) & \equiv v_{I}^{*}(I)-v_{U}^{*}(I) \\
& =E\left[v\left(\widetilde{q}_{\max }^{*}\right)\right]-v\left(\frac{E\left[\widetilde{q}_{\max }^{*}\right]}{n^{*}}\right)
\end{aligned}
$$

\footnotetext{
${ }^{18}$ Our qualitative results extend to heterogenous costs; see Appendix B.
} 
where $n^{*}=n^{*}(I)$. Since $v(q)$ is convex, $\Delta(I) \geq 0$. The donor pays for information if and only if $\Delta(I) \geq c$. Therefore, under endogenous information, a triplet $\left(I^{*}, n^{* *}, F^{* *}\right)$ constitutes a (Nash) equilibrium if:

- no charity has an incentive to enter or exit - i.e., $n^{* *}=n^{*}\left(I^{*}\right)$,

- no entrant has an incentive to deviate from symmetric mixing $F^{* *}=\left.F^{*}\right|_{I=I^{*}}$, and

- no uninformed donor has an incentive to be informed and no informed donor has an incentive to remain uninformed 19 in particular, the following must hold in equilibrium:

$$
\Delta\left(I^{*}\right)\left\{\begin{array}{lll}
\geq c & \text { if } & I^{*}=M \\
=c & \text { if } & 0<I^{*}<M \\
\leq c & \text { if } & I^{*}=0 .
\end{array}\right.
$$

Our first observation is that regardless of the information cost, there always exists a degenerate equilibrium in which the market fails.

Lemma 1 A degenerate equilibrium in which $\left(I^{*}, n^{* *}\right)=(0,0)$ always exists.

Proof. Given $I^{*}=0$, charity $i$ in the market would receive payoff: $R_{i}=\frac{M}{n^{* *}} g_{U}^{* *}-q_{i}-k$, which is maximized at $q_{i}=0$. But then no uninformed donor would make a positive contribution - i.e., $g_{U}^{* *}=0$, implying $R_{i}=-k<0$ and in turn $n^{* *}=0$. Conversely, given $n^{* *}=0$, staying uninformed is clearly a best response for each donor - i.e., $I^{*}=0$.

Lemma 1 follows because, as noted above, charities provide quality to win informed donors. In the absence of the latter, uninformed donors grow pessimistic about quality and are unwilling to contribute, which in turn deters entry.

An important corollary to Lemma 1 is that for the charitable market to exist, there must be some informed giving in equilibrium, $I^{*}>0$. In fact, as indicated in Proposition 2, informed giving must be significant, though not universal, to both accommodate entry and justify the cost of quality. Lemma 2 adds that for informed giving, at least two charities must be active.

\footnotetext{
${ }^{19}$ Here we implicitly assume a pure information acquisition decision but given a continuum of donors, this is strategically equivalent to having each mix and acquire information with probability $\frac{I^{*}}{M}$.
} 
Lemma 2 If $I^{*}>0$, then $n^{* *} \geq 2$ and $I_{L} \leq I^{*} \leq I_{H}$.

Proof. Suppose $I^{*}>0$. Then $n^{* *} \geq 1$ and $\Delta\left(I^{*}\right) \geq c$ by Lemma 1 and (15), respectively. If $n^{* *}=1$, the sole charity would set $q_{S}>0$ that uniquely maximizes $R_{\text {win }}^{* *}(q)=$ $I^{*} g(q)+\left(M-I^{*}\right) g_{U}^{* *}-q-k$. This implies that $q_{\max }^{* *}=q_{U}^{* *}$ and that $\Delta\left(I^{*}\right)=0$ from $14-$ a contradiction. Hence, $n^{* *} \geq 2$.

For donors to be interested in informed giving, there must be quality uncertainty. But this can only arise under competition; otherwise, having a single-peaked net revenue (see Figure 3), a single charity would choose a perfectly predictable quality, leading all donors to stay uninformed instead 20

Lemma 2 implies that in a nondegenerate equilibrium, $I^{*} \in(0, M)$ and therefore solves

$$
\Delta\left(I^{*}\right)=c
$$

In order to determine when a solution to (16) exists, let

$$
\Delta_{\min } \equiv \min _{I \in\left[I_{L}, I_{H}\right]} \Delta(I) \text { and } \Delta_{\max } \equiv \max _{I \in\left[I_{L}, I_{H}\right]} \Delta(I) .
$$

These extreme values of information are well-defined because $\Delta(I)$ is continuous. It is readily verified that $0<\Delta_{\min }<\Delta_{\max }<\infty$. From here, Proposition 5 is immediate.

Proposition 5 A nondegenerate equilibrium exists if and only if the information cost is moderate: $\Delta_{\min } \leq c \leq \Delta_{\max }$

Intuitively, if the information cost were too high, then donors would remain uninformed and without the informed, they would expect minimal quality of service and refrain from giving. If, on the other hand, the information cost were too low, charities would expect a much intense quality competition and with little uninformed giving, they would be unable to recoup their entry costs (however small they are). Proposition 5 thus suggests limited benefits of the freely available charity ratings. To understand this point further, we next study the effect of the information cost on informed giving and social welfare.

Given I, we define social welfare to be the sum of expected donors' payoffs:

$$
W(I) \equiv I\left[v_{I}^{*}(I)-c\right]+(M-I) v_{U}^{*}(I)
$$

\footnotetext{
${ }^{20}$ This feature of the model is reminiscent of the dynamics in a pure strategy equilibrium of a sequentialmove game, in which the follower may refrain from paying to observe the leader's action and thus engender a simultaneous-move outcome (e.g., Morgan and Vardy 2007).
} 
Since, in equilibrium, informed donors ignore their positive externality on others, the following inefficiency obtains.

Lemma 3 In equilibrium, too few donors become informed.

Proof. Differentiating (18) and evaluating at the equilibrium, we have $W^{\prime}\left(I^{*}\right)=I^{*} v_{I}^{* \prime}\left(I^{*}\right)+$ $\left(M-I^{*}\right) v_{U}^{* \prime}\left(I^{*}\right)>0$ by $(16)$ and Proposition $4(\mathrm{c})$.

In equilibrium, using $\Delta\left(I^{*}\right)=c$ from $(16),(18)$ reduces to:

$$
W\left(I^{*}\right)=M v_{U}^{*}\left(I^{*}\right)
$$

Informed giving improves donors' equilibrium welfare to the extent that it improves the uninformed payoff, $v_{U}^{*}(I)$. Any additional benefit is outweighed by its cost. Recall from Proposition 4(c) that the uninformed payoff is increasing in I. Eq.(19) therefore implies that a higher information cost will lower welfare if and only if it discourages informed giving. The latter depends critically on whether $\Delta^{\prime}(I)>0$ or $\Delta^{\prime}(I) \leq 0$ - i.e., whether donors' information decisions are strategic complements or substitutes. Under realistic conditions, information decisions are strategic complements, leading us to:

Proposition 6 Suppose $k$ is sufficiently small or that $r$ is sufficiently close to 1 . Then, there is a unique nondegenerate equilibrium for $c \in\left[\Delta_{\min }, \widehat{\Delta}\right)$, where $\widehat{\Delta} \in\left(\Delta_{\min }, \Delta_{\max }\right)$. In this region, the mass of informed donors, $I^{*}$, and social welfare, $W\left(I^{*}\right)$, are both increasing in $c$.

Proposition 6 says that higher information cost may encourage informed giving and raise total donors' welfare in turn! Suppose that the setup cost $k$ is negligible. Then Proposition 3 implies that a large number of charities enter the market, which completely discourages uninformed giving. Formally, for $k \approx 0$, we have $v_{U}^{*}(I) \approx 1$ and thus $\Delta(I) \approx$ $v_{I}^{*}(I)-1$, which clearly increases with $I$ and indicates that information acquisition decisions are strategic complements. From (16), the mass of informed donors is found to be

$$
I^{*} \approx v_{I}^{*-1}(1+c),
$$

which is clearly increasing in $c$.

The same comparative static also holds for a non-negligible setup cost if donors' preferences are (approximately) Cobb-Douglas, $r \approx 1$. The intuition is similar but slightly more involved in this case due to the fact that uninformed giving is significant. Notice that for 

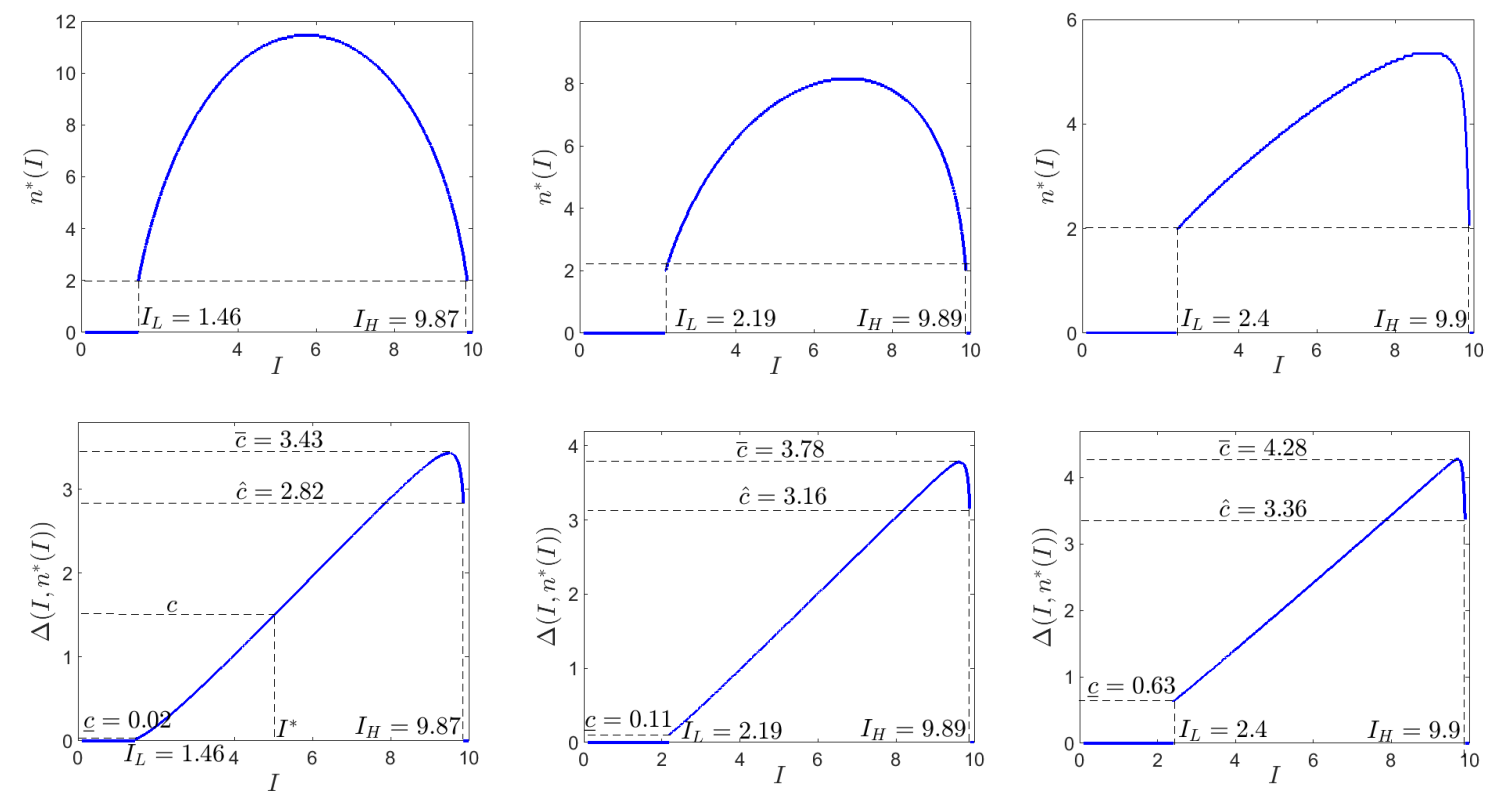

(a) $r=1.1$ and $k=0.05$

(b) $r=2$ and $k=0.05$

(c) $r=10$ and $k=0.05$

Figure 4: Value of information and equilibrium entry

$r \approx 1$, the indirect utility in 12 becomes $v(q) \approx 1+q$ and reduces the value of information to:

$$
\begin{aligned}
\Delta(I) & \approx\left(1+E\left[\widetilde{q}_{\max }^{*}\right]\right)-\left(1+\frac{E\left[\widetilde{q}_{\max }^{*}\right]}{n^{*}}\right) \\
& =\frac{n^{*}-1}{n^{*}} E\left[\widetilde{q}_{\max }^{*}\right] .
\end{aligned}
$$

Clearly, the value of information is increasing in the expected quality of service, $E\left[\widetilde{q}_{\max }^{*}\right]$, and number of fundraisers, $n^{*}$, because giving increases with quality but uninformed giving is discouraged as the number of charities grows. Under exogenous information, we know from Proposition 4 that $E\left[\widetilde{q}_{\max }^{*}\right]$ is increasing in the size of informed donors, $I$. We also know that $n^{*}=n^{*}(I)$ is single-peaked, so there is a threshold $\widehat{I}>I_{L}$ such that for $I \in\left(I_{L}, \widehat{I}\right), n^{*}(I)$ is also increasing in $I$, implying a higher value of information in this region, $d \Delta(I) / d I>0$. From (16), it therefore follows that $I^{*}$ rises with $c$ for some intermediate cost levels, as stated in Proposition 6.

This formal intuition is also illustrated in Figure 4(a) for $r=1.1, k=.05$ and $M=10$. Although we have been unable to prove this result for any $r>1$, Figures 4(b) and (c) suggest that strategic complementarity of information decisions will be pronounced even 
more for higher $r$ values ${ }^{21}$ Intuitively, as implied by (2), under a greater substitutability between private consumption and giving, donors grow more generous so long as the charity quality is sufficiently high -i.e., $q>1$. This additional giving compensates for the diminished uninformed giving and extends the region in which charity entry, and therefore the value of information, rises with the size of the informed.

Proposition 6 is important because the sheer number of charities alluded to in the Introduction suggests little entry cost into the market for donations. Indeed, after natural disasters and national tragedies, donors are often warned of charity fundraising scams 22 In such cases, Proposition 6 predicts that informed giving may be better promoted by less readily available charity evaluations.

\section{An extension: quality-adjusted provision}

Up to now, charities have been assumed to care only about the "quantity" of their service, $R_{i}$; they provide quality to satisfy the demand for it. Conceivably, charities may also have an intrinsic preference for quality. For instance, a homeless shelter may value not only how many needy it houses but also how well it houses them - e.g., families, youth, etc. We show that our results extend seamlessly to the following quality-adjusted provision:

$$
\bar{R}_{i}=\phi(q) R_{i}
$$

where $\phi^{\prime}(q)>0$ and $\phi(0)>0$. The latter rules out $\phi(0)=0$ to ensure that the charity cannot avoid entry cost by simply choosing $q=0$. As before, if $R_{i} \leq 0$, then no service is provided, irrespective of quality. To see the equivalence of the equilibrium with the base model, we recall the previous line of argument. Note that if charity $i$ sets quality $q$ and ranks the highest among $n^{*} \geq 2$, then it receives net revenues: $\bar{R}_{\text {win }}^{*}(q)=\phi(q) R_{\text {win }}^{*}(q)$. If it ranks lower, it receives net revenues: $\bar{R}_{\text {lose }}^{*}(q)=\phi(q) R_{\text {lose }}^{*}(q)$. The indifference equation to determine the equilibrium quality distribution $F^{*}$ therefore becomes

$$
\left(F^{*}\right)^{n^{*}-1}(q) \phi(q) R_{\text {win }}^{*}(q)+\left[1-\left(F^{*}\right)^{n^{*}-1}(q)\right] \phi(q) R_{\text {lose }}^{*}(q)=0
$$

which, canceling out $\phi(q)>0$ from the left-hand side, reduces to (8). Moreover, since $\phi(0)>0$, it is clear that the free-entry condition in (6) and thus (7) remain intact. Together,

\footnotetext{
${ }^{21}$ Andreoni and Miller (2002) and Fisman et al. (2007) experimentally study individual preferences for giving and estimate $r \geq 1$ for a majority of subjects.

${ }^{22}$ http:/ / www.huffingtonpost.com/2013/05/06/boston-marathon-charity-scams_n_3223366.html
} 
21) reveals that $F^{*}(q)$ is exactly as found in Proposition 1. Given this, it is immediate that the rest of the analysis, including endogenous information, continues to hold under this generalization.

\section{Conclusion}

Drawing upon the all-pay auction literature, especially Varian (1980) and Che and Gale (2003), this paper has offered a novel model of charity competition in which informed giving alone can explain the quality heterogeneity across similar charities and the demand for information in turn. We show that both uninformed and informed giving is necessary in this market: the former attracts entry whereas the latter induces quality provision. We also show that the increased competition decreases the quality of the charitable service and donors' welfare. In equilibrium, too few donors become informed; but interestingly, informed giving may increase with the cost of information. This is the case if the charitable market is highly competitive or if private consumption is a strong substitute to giving both of which are supported by evidence.

Our findings indicate that a $90 \%$ approval rate by the IRS for a charity status may adversely affect the quality of the charitable service. Although our model is too stylized to determine the socially optimal number of charities, it does starkly imply that only two charities may generate enough competition in quality ${ }^{23}$ Our findings also indicate a positive but limited role for rating agencies in promoting informed giving - a point that calls for empirical investigation.

\footnotetext{
${ }^{23}$ This is in line with Che and Gale's (2003) prediction that the optimal number of contestants in a research tournament is two.
} 


\section{Appendix A: Proofs}

We begin with two auxiliary lemmas.

Lemma A1. Let $\widetilde{y}_{1}, \ldots, \widetilde{y}_{n}$ be nonnegative iid random variables, with cdf $\widehat{F}$ and $p d f \widehat{f}$. Moreover, $\widehat{f}$ is continuous in $\left[y_{L}, y_{H}\right]$ and has a mass point at $y=0$. Then

$$
E\left[\widetilde{y}_{\max }\right]=\int_{y_{L}}^{y_{H}} y d \widehat{F}^{n}(y)
$$

where $\widetilde{y}_{\max } \equiv \max \left\{\widetilde{y}_{1}, \ldots, \widetilde{y}_{n}\right\}$.

Proof. Define the conditional distribution: $J(y)=\frac{\widehat{F}(y)-\widehat{F}\left(y_{L}\right)}{1-\widehat{F}\left(y_{L}\right)}, y \in\left[y_{L}, y_{H}\right]$. Suppose exactly $k$ out of $n$ random variables have $y>y_{L}$. Then,

$$
G(y ; k) \equiv \operatorname{Pr}\left\{\widetilde{y}_{\max } \in\left(y_{L}, y\right)\right\}=J^{k}(y)
$$

and

$$
\begin{aligned}
G^{\prime}(y ; k) & =k J^{\prime}(y) J^{k-1}(y) \\
& =k\left(\frac{\widehat{f}(y)}{1-\widehat{F}\left(y_{L}\right)}\right)\left(\frac{\widehat{F}(y)-\widehat{F}\left(y_{L}\right)}{1-\widehat{F}\left(y_{L}\right)}\right)^{k-1} \\
& =k \frac{\widehat{f}(y)\left(\widehat{F}(y)-\widehat{F}\left(y_{L}\right)\right)^{k-1}}{\left(1-\widehat{F}\left(y_{L}\right)\right)^{k}} .
\end{aligned}
$$

Note that

$$
E\left[\widetilde{y}_{\max }\right]=\sum_{k=1}^{n}\left(\begin{array}{l}
n \\
k
\end{array}\right)\left(1-\widehat{F}\left(y_{L}\right)\right)^{k}\left(\widehat{F}\left(y_{L}\right)\right)^{n-k} E\left[\widetilde{y}_{\max } \mid k\right]
$$

where $E\left[\widetilde{y}_{\max } \mid k\right]=\int_{y_{L}}^{y_{H}} y d G(y ; k)$. Then

$$
\begin{aligned}
E\left[\widetilde{y}_{\text {max }}\right] & =\sum_{k=1}^{n}\left(\begin{array}{l}
n \\
k
\end{array}\right)\left(\widehat{F}\left(y_{L}\right)\right)^{n-k} \int_{y_{L}}^{y_{H}} k y \widehat{f}(y)\left(\widehat{F}(y)-\widehat{F}\left(y_{L}\right)\right)^{k-1} d y \\
& =\int_{y_{L}}^{y_{H}} y \widehat{f}(y)\left(\sum_{k=1}^{n}\left(\begin{array}{l}
n \\
k
\end{array}\right)\left(\widehat{F}\left(y_{L}\right)\right)^{n-k} k\left(\widehat{F}(y)-\widehat{F}\left(y_{L}\right)\right)^{k-1}\right) d y .
\end{aligned}
$$

Finally, since $k\left(\begin{array}{l}n \\ k\end{array}\right)=n\left(\begin{array}{l}n-1 \\ k-1\end{array}\right)$, we have

$$
\begin{aligned}
\sum_{k=1}^{n}\left(\begin{array}{l}
n \\
k
\end{array}\right)\left(\widehat{F}\left(y_{L}\right)\right)^{n-k} k\left(\widehat{F}(y)-\widehat{F}\left(y_{L}\right)\right)^{k-1} & =n \sum_{k=1}^{n}\left(\begin{array}{c}
n-1 \\
k-1
\end{array}\right)\left(\widehat{F}\left(y_{L}\right)\right)^{n-k}\left(\widehat{F}(y)-\widehat{F}\left(y_{L}\right)\right)^{k-1} \\
& =n \sum_{k=0}^{n-1}\left(\begin{array}{c}
n-1 \\
k
\end{array}\right)\left(\widehat{F}\left(y_{L}\right)\right)^{n-1-k}\left(\widehat{F}(y)-\widehat{F}\left(y_{L}\right)\right)^{k} \\
& =n \widehat{F}^{n-1}(y)
\end{aligned}
$$


where the last line follows from the Binomial Theorem.

Lemma A2. Let $q_{L}=(r-1)^{\frac{1}{r}}, I_{C}=r(r-1)^{\frac{1}{r}-1}$, and $q_{H}$ be the largest root to $\operatorname{Ig}(q)-q=0$. Also let each charity continuously mix over $q \in\left[q_{L}, q_{H}\right]$ according to

$$
F(q)=\left(\frac{q}{\operatorname{Ig}(q)}\right)^{\frac{1}{n-1}}
$$

and have a mass point at $q=0$ with $F(0)=F\left(q_{L}\right)$. Then, for $I>I_{C}$,
(a) $\lim _{I \rightarrow I_{c}} q_{H}=q_{L}$.
(b) $q_{H}<I$ and $\frac{\partial q_{H}}{\partial I}>0$.
(c) $\frac{\partial E\left[\widetilde{q}_{\max }\right]}{\partial I}>0$.
(d) $\frac{\partial E\left[\widetilde{q}_{\max }\right]}{\partial n}<0$ and $\lim _{n \rightarrow \infty} E\left[\widetilde{q}_{\max }\right]=\frac{1}{I} \int_{q_{L}}^{q_{H}}\left(q+(1-r) q^{1-r}\right) d q>0$.

Proof. Re-writing, $I g(q)-q=\frac{q}{1+q^{r}} \Omega(q)$ where $\Omega(q)=q^{r-1} I-\left(1+q^{r}\right) . \Omega(q)$ is maximized at $q^{*}=\frac{r-1}{r} I$, with $\Omega\left(q^{*}\right)=\left(\frac{I}{I_{c}}\right)^{r}-1$. If $I \leq I_{c}$, then $\Omega(q) \leq 0$ for all $q$, which implies $q_{H}=0$. If $I>I_{c}$, then $\Omega(q)>0$ for some $q>0$, which implies $q_{H}>0$. Clearly, $\lim _{I \rightarrow I_{c}} q^{*}=q_{L}$ and $\lim _{I \rightarrow I_{c}} \Omega\left(q^{*}\right)=0$. Hence, $\lim _{I \rightarrow I_{c}} q_{H}=q_{L}$.

To prove part (b), note that $q_{H}=I g\left(q_{H}\right)<I$. Differentiating with respect to $I$ yields,

$$
\left.\frac{\partial q_{H}}{\partial I}=\frac{q_{H}^{r}}{1-r+q_{H}^{r}}>0 \text { (because } q_{H}>q_{L}\right)
$$

Using this fact, Lemma A1 and that $\partial F^{n}(q) / \partial I<0$, we prove part (c). Finally, $\frac{\partial E\left[\widetilde{q}_{\max }\right]}{\partial n}<0$ follows from $\frac{\partial F^{n}(q)}{\partial n}>0$ while the limit of $E\left[\widetilde{q}_{\max }\right]$ obtains by observing that $F^{n}(q) \rightarrow \frac{q}{I g(q)}$ as $n \rightarrow \infty$.

Proof of Proposition 1. Consider a symmetric equilibrium with $n^{*} \geq 2$. We begin with part (c). As in standard all-pay auctions, no symmetric equilibrium in pure strategies exists in quality competition: given others' quality choices, fundraiser $i$ would have a strict incentive to slightly increase his and win all of informed donations. In equilibrium, let each fundraiser mix according to $F^{*}(q)$ and $S$ be its support. Clearly, due to free entry, the (common) expected payoff across quality choices in $S$ is $\pi=0$. Moreover, a standard argument from all-pay auctions reveals that $F^{*}(q)$ cannot admit a mass point at $q>0$; otherwise, fundraiser $i$ could shift weight to $q+\varepsilon$ and discretely increase his probability of 
winning informed donations while raising cost only by $\varepsilon$. From (4) and (5), the expected payoff of a fundraiser thus satisfies

$$
\left(F^{*}\right)^{n^{*}-1}(q) \operatorname{Ig}(q)+\frac{U}{n^{*}} g_{U}^{*}-k-q=0 \text { for all } q \in S^{+}
$$

where $S^{+} \equiv\{q \in S \mid q>0\}$.

Note that since a fundraiser could enter the market and choose $q=0$, it must be that

$$
\frac{U}{n^{*}} g_{U}^{*}-k \leq 0
$$

Together with A-2, A-1 implies that $F^{*}(q)>0$ for all $q \in S^{+}$. Then $q=0$ must be in $S$ and have a probability mass. In particular, letting $q_{L}<q_{H}$ be the lower and upper bounds of $S^{+}$, we have $F(0)=F\left(q_{L}\right)$, as stated in part (c).

Setting $q=0$ in $(\mathrm{A}-1),(\mathrm{A}-2)$ reduces to:

$$
\frac{U}{n^{*}} g_{U}^{*}-k=0
$$

as stated in part (b). Using (A-3, (A-1) reduces to:

$$
\left(F^{*}\right)^{n^{*}-1}(q) \operatorname{Ig}(q)-q=0
$$

from which the cdf in part (c) obtains. Substituting for (2) and differentiating, we find the pdf:

$$
F^{* \prime}(q)=\frac{1}{n^{*}-1}\left(\frac{1-r+q^{r}}{q\left(1+q^{r}\right)}\right) F^{*}(q) \text { for } q \in S^{+} .
$$

The continuous mixing over $S^{+}$requires that $F^{* \prime}(q)>0$ in its interior, which in turn requires that $q_{L} \geq(r-1)^{\frac{1}{r}}$. Suppose that $q_{L}>(r-1)^{\frac{1}{r}}$. Then fundraiser $i^{\prime}$ s expected payoff from a deviation to $q \in\left(0, q_{L}\right)$ is

$$
\pi_{i}^{d}\left(q, q_{L}\right)=\left(F^{*}\left(q_{L}\right)\right)^{n^{*}-1} \operatorname{Ig}(q)-q .
$$

Simple algebra shows

$$
\begin{aligned}
\left.\frac{\partial}{\partial q} \pi_{i}^{d}\left(q, q_{L}\right)\right|_{q=q_{L}} & =\frac{r}{1+q_{L}^{r}}-1 \\
& <\frac{r}{1+\left((r-1)^{\frac{1}{r}}\right)^{r}}-1 \\
& =0 .
\end{aligned}
$$


This means that there exists some $q \in\left(0, q_{L}\right)$ such that $\pi_{i}^{d}\left(q, q_{L}\right)>\pi_{i}^{d}\left(q_{L}, q_{L}\right)=0$, contradicting $q_{L}$ being in $S^{+}$. Thus $q_{L}=(r-1)^{\frac{1}{r}}$.

To complete the proof of part (a), note that $R_{\text {lose }}^{*}(q)=-q$ by using $(\mathrm{A}-3)$. Therefore, only the highest quality fundraiser will provide charitable service. The informed donor ascertains the winner before giving while the uninformed donor picks him with probability $\frac{1}{n^{*}}$. This explains their optimal gifts in part (a).

To complete the proof of part (b), we substitute from (10) into (A-3) and write

$$
h\left(n^{*} ; I\right) \equiv \frac{M-I}{n^{*}} \frac{\left(E\left[\widetilde{q}_{\max }^{*}\right] / n^{*}\right)^{r}}{1+\left(E\left[\widetilde{q}_{\max }^{*}\right] / n^{*}\right)^{r}}-k=0 .
$$

From part (d) of Lemma A2,

$$
\frac{\partial h\left(n^{*} ; I .\right)}{\partial n^{*}}<0 \text { and } \lim _{n^{*} \rightarrow \infty} h\left(n^{*} ; I\right)=-k
$$

Therefore, a symmetric equilibrium with $n^{*} \geq 2$ requires $h(2 ; I) \geq 0$. Then, by $\mathrm{A}-5$ there is a unique $n^{*}$ that solves $h\left(n^{*} ; I\right)=0$, proving part (b). Since $n^{*}$ uniquely pins down $F^{*}(q)$ and the gifts, there is also a unique symmetric equilibrium.

Lemma A3. Let $n^{*} \geq 2$. Then, $h\left(n^{*} ; I\right)$, defined as in (A-4), is continuous and single-peaked in $I$ with $h\left(n^{*} ; I\right)=-k$ for $I \in\left[0, I_{c}\right] \cup\{M\}$.

Proof. Let $n^{*} \geq 2$. If $E\left[\widetilde{q}_{\max }^{*}\right]$ is continuous in $I$, so is $h\left(n^{*} ; I\right)$. By Lemma A2, $E\left[\widetilde{q}_{\max }^{*}\right]$ is continuous for $I>I_{c}$. For $I \leq I_{c}, E\left[\widetilde{q}_{\max }^{*}\right]=0$ and thus $h\left(n^{*} ; I\right)=-k$. Moreover, $\lim _{I \rightarrow I_{c}} E\left[\widetilde{q}_{\max }^{*}\right]=0$, which implies the continuity of $E\left[\widetilde{q}_{\max }^{*}\right]$ and $h\left(n^{*} ; I\right)$ at $I=I_{c}$. The fact that $h\left(n^{*} ; M\right)=-k$ follows by recalling $E\left[\widetilde{q}_{\max }^{*}\right]<\infty$ from Lemma A2.

To show the single-peakedness, we re-write $h\left(n^{*} ; I\right)=\frac{M-I}{n^{*}} \frac{\left(q_{U}^{*}\right)^{r}}{1+\left(q_{U}^{*}\right)^{r}}-k$. Differentiating with respect to $I$,

$$
\frac{\partial h\left(n^{*} ; I\right)}{\partial I}={ }^{\operatorname{sig} n} \underbrace{(M-I) r \frac{\partial q_{U}^{*}}{\partial I}}_{\Lambda\left(n^{*}, I\right)}-\underbrace{q_{U}^{*}\left(1+\left(q_{U}^{*}\right)^{r}\right)}_{\mathrm{Y}\left(n^{*}, I\right)} .
$$

Recalling $q_{U}^{*}=\frac{E\left[\tilde{q}_{\text {max }}^{*}\right]}{n^{*}}$ and using Lemma 1, simple algebra shows

$$
\frac{\partial q_{U}^{*}}{\partial I}=\frac{q_{H}-n^{*} q_{U}^{*}}{\left(n^{*}-1\right) I}>0
$$

From Lemma A2, $\lim _{I \rightarrow I_{c}} q_{H}=q_{L}>0$, revealing $\lim _{I \rightarrow I_{c}} q_{U}^{*}=0$. Therefore, $\lim _{I \rightarrow I_{c}} \frac{\partial h\left(n^{*} ; I\right)}{\partial I}>$ 0 . Moreover, $\frac{\partial h\left(n^{*} ; M\right)}{\partial I}<0$ from $\mathrm{A}-6$, which, by continuity, implies that $\frac{\partial h\left(n^{*} ; I\right)}{\partial I}=0$ has a 
solution $I \in\left(I_{c}, M\right)$. For single-peakedness of $h\left(n^{*} ; I\right)$, it suffices to prove that this solution is unique.

Suppose, to the contrary, that there are two roots $I^{\prime}<I^{\prime \prime}$ to $\frac{\partial h\left(n^{*} ; I\right)}{\partial I}=0$. To ease notation, define $\Phi\left(n^{*}, I\right)=\Lambda\left(n^{*}, I\right)-\mathrm{Y}\left(n^{*}, I\right)$. Since $\Phi\left(n^{*}, I\right)>0$ for $I \in\left(I_{c}, I^{\prime}\right)$ and $\frac{\partial \Phi\left(n^{*}, I^{\prime}\right)}{\partial I}<0, h\left(n^{*} ; I\right)$ reaches a local maximum at $I^{\prime}$. Simple differentiation yields

$$
\begin{gathered}
\frac{\partial \Lambda\left(n^{*}, I\right)}{\partial I}=-r \frac{\partial q_{U}^{*}}{\partial I}+r(M-I) \frac{\partial^{2} q_{U}^{*}}{\partial I^{2}} \\
\frac{\partial Y\left(n^{*}, I\right)}{\partial I}=\frac{\partial q_{U}^{*}}{\partial I}\left[1+(r+1)\left(q_{U}^{*}\right)^{r}\right]>0
\end{gathered}
$$

where $\frac{\partial^{2} q_{U}^{*}}{\partial I^{2}}=\frac{1}{(n-1) I}\left[-(2 n-1) \frac{\partial q_{U}}{\partial I}+\frac{\partial q_{H}}{\partial I}\right]$ from A-7) and $\frac{\partial q_{H}}{\partial I}>0$ from Lemma A2.

If $\frac{\partial \Phi\left(n^{*}, I\right)}{\partial I} \leq 0$ for all $I \in\left(I^{\prime}, M\right)$, then $\Phi\left(n^{*}, I\right)<0$ and $I^{\prime}$ is the unique solution. Hence, $\frac{\partial \Phi\left(n^{*}, I^{\prime \prime}\right)}{\partial I}>0$. Together with $\frac{\partial \Phi\left(n, I^{\prime \prime}\right)}{\partial I}>0$, this implies the existence of some $I^{\prime \prime \prime} \in\left(I^{\prime}, I^{\prime \prime}\right)$ such that $\frac{\partial \Phi\left(n^{*}, I^{\prime \prime \prime}\right)}{\partial I}=0$ and $\frac{\partial^{2} \Phi\left(n^{*}, I^{\prime \prime \prime}\right)}{\partial^{2} I}>0$. Since $\frac{\partial Y\left(n^{*}, I\right)}{\partial I}>0$, we have $\frac{\partial \Lambda\left(n, I^{\prime \prime \prime}\right)}{\partial I}>0$, which, from $(\mathrm{A}-8)$, implies $\left.\frac{\partial^{2} q_{u}^{*}}{\partial I^{2}}\right|_{I=I^{\prime \prime \prime}}>0$.

Further differentiating (A-8) and (A-9),

$$
\begin{gathered}
\frac{\partial^{2} \Lambda\left(n^{*}, I\right)}{\partial I^{2}}=-2 r \frac{\partial^{2} q_{U}^{*}}{\partial I^{2}}+r(M-I) \frac{\partial^{3} q_{U}^{*}}{\partial I^{3}} \\
\frac{\partial^{2} Y\left(n^{*}, I\right)}{\partial I^{2}}=\frac{\partial^{2} q_{U}^{*}}{\partial I^{2}}\left[1+(r+1) q_{U}^{r}\right]+(r+1)\left(\frac{\partial q_{U}^{*}}{\partial I}\right)^{2} .
\end{gathered}
$$

Since $\left.\frac{\partial^{2} q_{U}^{*}}{\partial I^{2}}\right|_{I=I^{\prime \prime \prime}}>0, \frac{\partial^{2} Y\left(n^{*}, I^{\prime \prime \prime}\right)}{\partial I^{2}}>0$. Moreover,

$$
\frac{\partial^{3} q_{U}^{*}}{\partial I^{3}}=-\frac{1}{I} \frac{\partial^{2} q_{U}^{*}}{\partial I^{2}}-\frac{2 n-1}{(n-1) I} \frac{\partial^{2} q_{U}^{*}}{\partial I^{2}}+\frac{1}{(n-1) I} \frac{\partial^{2} q_{H}}{\partial I^{2}}
$$

where $\frac{\partial^{2} q_{H}}{\partial I^{2}}=-\frac{r(r-1) q_{H}^{r}}{1-r+q_{H}^{r}} \frac{\partial q_{H}}{\partial I}<0$. Therefore, $\left.\frac{\partial^{2} q_{U}^{*}}{\partial I^{2}}\right|_{I=I^{\prime \prime \prime}}>0,\left.\frac{\partial^{3} q_{U}^{*}}{\partial I^{3}}\right|_{I=I^{\prime \prime \prime}}<0$, and $\frac{\partial^{2} \Lambda\left(n^{*}, I^{\prime \prime \prime}\right)}{\partial I^{2}}<$ 0 . This, however, requires $\frac{\partial^{2} \Phi\left(n^{*}, I^{\prime \prime \prime}\right)}{\partial I^{2}}<0$, yielding a contradiction. Hence, there is no $I^{\prime \prime} \in\left(I^{\prime}, M\right)$ such that $\frac{\partial \Phi\left(n^{*}, I^{\prime \prime}\right)}{\partial I}>0$, contradicting $\Phi\left(n^{*}, I^{\prime \prime}\right)=0$. This implies a unique $I^{\prime}$ that solves $\Phi\left(n^{*}, I^{\prime}\right)=0$, proving that $h\left(n^{*} ; I\right)$ is single-peaked in $I$.

Proof of Proposition 2. Immediately follows from (A-5) and Lemma A3.

Proof of Proposition 3. Suppose $I_{L} \leq I \leq I_{H}$. Implicitly differentiating (A-4), we have $\frac{\partial n^{*}}{\partial k}=\frac{1}{\partial h\left(n^{*} ; I, r\right) / \partial n^{*}}<0$. Since $E\left[\widetilde{q}_{\max }^{*}\right]<\infty$, we also have $\lim _{k \rightarrow 0} n^{*}=\infty$. Part (b) is immediate from Lemma A2. To prove part (c), note from 13 that $\frac{\partial v_{U}^{*}}{\partial k}=\left(1+q_{U}^{* r}\right)^{\frac{1}{r}-1} q_{U}^{* r-1} \frac{\partial q_{U}^{*}}{\partial n} \frac{\partial n^{*}}{\partial k}>$ 0 , where the inequality follows because $\frac{\partial q_{U}^{*}}{\partial n^{*}}<0$ and $\frac{\partial n^{*}}{\partial k}<0$. For the informed donor, 


$$
v_{I}^{*}=v(0) F^{n^{*}}\left(q_{L}\right)+\int_{q_{L}}^{q_{H}} v(q) d F^{n^{*}}(q)
$$

where $v(q)$ is the indirect utility in (12). Integrating by parts,

$$
v_{I}^{*}=v\left(q_{H}\right)-\left[v\left(q_{L}\right)-v(0)\right] F^{n^{*}}\left(q_{L}\right)-\int_{q_{L}}^{q_{H}} v^{\prime}(q) F^{n^{*}}(q) d q
$$

where $v\left(q_{L}\right)-v(0)>0$ since $v^{\prime}(q)>0$. Moreover, $\frac{\partial v_{I}^{*}}{\partial n^{*}}<0$ since $\frac{\partial F^{n^{*}}(q)}{\partial n^{*}}>0$. Hence, $\frac{\partial v_{I}^{*}}{\partial k}=$ $\frac{\partial v_{I}^{*}}{\partial n^{*}} \frac{\partial n^{*}}{\partial k}>0$, as desired.

Proof of Proposition 4. Suppose $I_{L} \leq I \leq I_{H}$. To prove part (a), note from (A-4) that $\frac{\partial n^{*}}{\partial I}=-\frac{\partial h\left(n^{*} ; I\right) / \partial I}{\partial h\left(n^{*} ; I\right) / \partial n^{*}}$. Since $\frac{\partial h\left(n^{*} ; I\right)}{\partial n^{*}}<0$ and $h\left(n^{*} ; I\right)$ is single-peaked in $I$ ( Lemma A3), $n^{*}$ is single-peaked in $I$, too.

To prove part (b), observe that $\frac{d E\left[\tilde{q}_{\max }^{*}\right]}{d I}=\frac{\partial E\left[\widetilde{q}_{\max }^{*}\right]}{\partial I}+\frac{\partial E\left[\widetilde{q}_{\max }^{*}\right]}{\partial n^{*}} \frac{\partial n^{*}}{\partial I}$. By Lemma A2, $\frac{\partial E\left[\widetilde{q}_{\max }^{*}\right]}{\partial I}>$ 0 and $\frac{\partial E\left[\widetilde{q}_{\max }^{*}\right]}{\partial n^{*}}<0$. If $\frac{\partial n^{*}}{\partial I} \leq 0$, it follows that $\frac{d E\left[\tilde{q}_{\max }^{*}\right]}{d I}>0$. Suppose $\frac{\partial n^{*}}{\partial I}>0$. Re-writing [11,

$$
g\left(\frac{E\left[\widetilde{q}_{\max }^{*}\right]}{n^{*}}\right)=\frac{k n^{*}}{M-I} .
$$

Differentiating both sides with respect to $I$,

$$
g^{\prime}\left(\frac{E\left[\widetilde{q}_{\max }^{*}\right]}{n^{*}}\right) \frac{d}{d I}\left(\frac{E\left[\widetilde{q}_{\max }^{*}\right]}{n^{*}}\right)=\frac{k\left[n^{*}+(M-I) \frac{\partial n^{*}}{\partial I}\right]}{(M-I)^{2}}>0 .
$$

Note that $g^{\prime}(q)>0$ and $\frac{\partial n^{*}}{\partial I}>0$ imply that $\frac{d}{d I}\left(\frac{E\left[\widetilde{q}_{\max }^{*}\right]}{n^{*}}\right)>0$. Moreover, $\frac{d}{d I}\left(\frac{E\left[\tilde{q}_{\max }^{*}\right]}{n^{*}}\right)=$ $\frac{1}{n^{*}}\left(\frac{d E\left[\tilde{q}_{\max }^{*}\right]}{d I}-\frac{E\left[\widetilde{q}_{\max }^{*}\right]}{n^{*}} \frac{\partial n^{*}}{\partial I}\right)>0$, which implies that $\frac{d E\left[\tilde{q}_{\max }^{*}\right]}{d I}>\frac{E\left[\tilde{q}_{\max }^{*}\right]}{n^{*}} \frac{\partial n^{*}}{\partial I}>0$, proving part (b).

To prove part c), consider first the uninformed donor. By $(13) v_{U}^{*}(I)=v\left(q_{U}^{*}\right)$ is increasing in $q_{U}^{*}$. From the proof of part $(\mathrm{b}), \frac{d q_{U}^{*}}{d I}=\frac{d}{d I}\left(\frac{E\left[\tilde{q}_{\max }^{*}\right]}{n^{*}}\right)>0$. Therefore, $\frac{d v_{U}^{*}(I)}{d I}>0$. Next consider the informed donor. By (A-11),

$$
\frac{d v_{I}^{*}(I)}{d I}=-\left[v\left(q_{L}\right)-v(0)\right] \frac{d F^{n^{*}}\left(q_{L}\right)}{d I}-\int_{q_{L}}^{q_{H}} \frac{\partial v(q)}{\partial q} \frac{d F^{n^{*}}(q)}{d I} d q .
$$

Therefore, $\frac{d v_{I}^{*}(I)}{d I}>0$ if $\frac{d F^{n^{*}}(q)}{d I}<0$ for all $q \in\left[q_{L}, q_{H}\right]$. 


$$
\begin{aligned}
\frac{d F^{n^{*}}(q)}{d I} & =\frac{\partial F^{n^{*}}(q)}{\partial I}+\frac{\partial F^{n^{*}}(q)}{\partial n^{*}} \frac{\partial n^{*}}{\partial I} \\
& =-\frac{n^{*}}{\left(n^{*}-1\right) I} F^{n^{*}}(q)-F^{n^{*}}(q) \ln \left(\frac{1+q^{r}}{q^{r-1} I}\right) \frac{1}{\left(n^{*}-1\right)^{2}} \frac{\partial n^{*}}{\partial I} \\
& =-\frac{1}{\left(n^{*}-1\right)^{2}} F^{n^{*}}(q)\left(\frac{\left(n^{*}-1\right) n^{*}}{I}+\ln \left(\frac{1+q^{r}}{q^{r-1} I}\right) \frac{\partial n^{*}}{\partial I}\right) .
\end{aligned}
$$

For $\frac{\partial n^{*}}{\partial I}<0, \frac{d F^{n^{*}}(q)}{d I}<0$ for all $q \in\left[q_{L}, q_{H}\right]$ and $\frac{d v_{I}^{*}(I)}{d I}>0$. For $\frac{\partial n^{*}}{\partial I}>0, \lim _{q \rightarrow 0} \frac{d F^{n^{*}}(q)}{d I}=\infty$ and $\frac{d F^{n^{*}}\left(q_{H}\right)}{d I}=-\frac{n^{*}}{\left(n^{*}-1\right) I}<0$. Moreover, $\frac{\left(n^{*}-1\right) n^{*}}{I}-\ln \left(\frac{1+q^{r}}{q^{r-1} I}\right) \frac{\partial n^{*}}{\partial I}$ is increasing in $q$. Therefore, by continuity, there exists $\tilde{q}(I)$ such that $\frac{d F^{n^{*}}(q)}{d I}>0$ for $q<\tilde{q}(I)$ and $\frac{d F^{n^{*}}(q)}{d I}<0$ for $q>\tilde{q}(I)$.

Consider $I^{\prime \prime}>I^{\prime}$ such that $n^{*}\left(I^{\prime \prime}\right)>n^{*}\left(I^{\prime}\right)$. Then, by A-11

$$
\begin{aligned}
v_{I}^{*}\left(I^{\prime \prime}\right)-v_{I}^{*}\left(I^{\prime}\right)= & v\left(q_{H}^{\prime \prime}\right)-v\left(q_{H}^{\prime}\right)-\left[v\left(q_{L}\right)-v(0)\right]\left[F^{n^{*}}\left(q_{L} \mid I^{\prime \prime}\right)-F^{n^{*}}\left(q_{L} \mid I^{\prime}\right)\right] \\
& -\int_{q_{H}^{\prime}}^{q_{H}^{\prime \prime}} \frac{\partial v(q)}{\partial q}\left[F^{n^{*}}\left(q \mid I^{\prime \prime}\right)-F^{n^{*}}\left(q \mid I^{\prime}\right)\right] d q-\int_{q_{H}^{\prime}}^{q_{H}^{\prime \prime}} \frac{\partial v(q)}{\partial q} F^{n^{*}}\left(q \mid I^{\prime \prime}\right) d q .
\end{aligned}
$$

Since $v^{\prime}(q)>0, v\left(q_{H}^{\prime \prime}\right)-v\left(q_{H}^{\prime}\right)-\int_{q_{H}^{\prime}}^{q_{H}^{\prime \prime}} \frac{\partial v(q)}{\partial q} F^{n^{*}}\left(q \mid I^{\prime \prime}\right) d q=-v\left(q_{H}^{\prime}\right)\left[1-F^{n^{*}}\left(q_{H}^{\prime} \mid I^{\prime \prime}\right)\right]+\int_{q_{H}^{\prime}}^{q_{H}} v(q) d F^{n^{*}}\left(q \mid I^{\prime \prime}\right)>$ 0 . Therefore,

$$
\begin{aligned}
v_{I}^{*}\left(I^{\prime \prime}\right)-v_{I}^{*}\left(I^{\prime}\right)= & -\left[v\left(q_{L}\right)-v(0)\right]\left[F^{n^{*}}\left(q_{L} \mid I^{\prime \prime}\right)-F^{n^{*}}\left(q_{L} \mid I^{\prime}\right)\right] \\
& -\int_{q_{H}^{\prime}}^{q_{H}^{\prime \prime}} \frac{\partial v(q)}{\partial q}\left[F^{n^{*}}\left(q \mid I^{\prime \prime}\right)-F^{n^{*}}\left(q \mid I^{\prime}\right)\right] d q \\
& -v\left(q_{H}^{\prime}\right)\left[1-F^{n^{*}}\left(q_{H}^{\prime} \mid I^{\prime \prime}\right)\right]+\int_{q_{H}^{\prime}}^{q_{H}} v(q) d F^{n^{*}}\left(q \mid I^{\prime \prime}\right) .
\end{aligned}
$$

If $F^{n^{*}}\left(q \mid I^{\prime \prime}\right) \leq F^{n^{*}}\left(q \mid I^{\prime}\right)$ for $q=q_{L}$, then clearly $v_{I}^{*}\left(I^{\prime \prime}\right)>v_{I}^{*}\left(I^{\prime}\right)$. Suppose instead that $F^{n^{*}}\left(q \mid I^{\prime \prime}\right)>F^{n^{*}}\left(q \mid I^{\prime}\right)$ for $q<\hat{q} \in\left(q_{L}, q_{H}^{\prime}\right)$. Let $\xi(q)=a+b q$ with the property $\xi\left(q_{L}\right)=$ $v\left(q_{L}\right)$ and $\frac{\partial \xi(\hat{q})}{\partial q}=b=\frac{\partial v(\hat{q})}{\partial q}$. These two equations completely determine the values of $a$ and b. Moreover,

$$
E[\xi(q) \mid I]=a+b E\left[\widetilde{q}_{\max }^{*}\right] .
$$

Since $E\left[\widetilde{q}_{\text {max }}^{*}\right]$ is strictly increasing in $I$ in equilibrium, $E\left[\xi(q) \mid I^{\prime \prime}\right]>E\left[\xi(q) \mid I^{\prime}\right]$. We want to show that $v_{I}^{*}\left(I^{\prime \prime}\right)-v_{I}^{*}\left(I^{\prime}\right)>E\left[\xi(q) \mid I^{\prime \prime}\right]-E\left[\xi(q) \mid I^{\prime}\right]>0$. This is equivalent to showing 
$v_{I}^{*}\left(I^{\prime \prime}\right)-E\left[\xi(q) \mid I^{\prime \prime}\right]>v_{I}^{*}\left(I^{\prime}\right)-E\left[\xi(q) \mid I^{\prime}\right]$. By $\mathrm{A}-11$,

$$
\begin{aligned}
v_{I}^{*}(I)-E[\xi(q) \mid I]= & v\left(q_{H}\right)-\xi\left(q_{H}\right)+(v(0)-\xi(0)) F^{n^{*}}\left(q_{L} \mid I\right) \\
& -\int_{q_{L}}^{q_{H}}\left(v^{\prime}(q)-\xi^{\prime}(q)\right) F^{n^{*}}(q \mid I) d q
\end{aligned}
$$

where we used $v\left(q_{L}\right)=\xi\left(q_{L}\right)$. Note that the strict convexity of $v(q)$ and linearity of $\xi(q)$ imply that $v^{\prime}(q)<\xi^{\prime}(q)$ for $q<\hat{q}$. Moreover, $v\left(q_{L}\right)=\xi\left(q_{L}\right)$ and $v^{\prime}(q)<\xi^{\prime}(q)$ imply that $v(0)-\xi(0)>0$. Then, we can write

$$
\begin{aligned}
& \left(v_{I}^{*}\left(I^{\prime \prime}\right)-E\left[\xi(q) \mid I^{\prime \prime}\right]\right)-\left(v_{I}^{*}\left(I^{\prime}\right)-E[\xi(q) \mid I]\right)= \\
& {\left[v\left(q_{H}^{\prime \prime}\right)-\xi\left(q_{H}^{\prime \prime}\right)\right]-\left[v\left(q_{H}^{\prime}\right)-\xi\left(q_{H}^{\prime}\right)\right]+[v(0)-\xi(0)]\left[F^{n^{*}}\left(q_{L} \mid I^{\prime \prime}\right)-F^{n^{*}}\left(q_{L} \mid I^{\prime}\right)\right]} \\
& -\int_{q_{L}}^{q_{H}^{\prime}}\left(v^{\prime}(q)-\xi^{\prime}(q)\right)\left[F^{n^{*}}\left(q \mid I^{\prime \prime}\right)-F^{n^{*}}\left(q \mid I^{\prime}\right)\right] d q-\int_{q_{H}^{\prime}}^{q_{H}^{\prime \prime}}\left(v^{\prime}(q)-\xi^{\prime}(q)\right) F^{n^{*}}\left(q \mid I^{\prime \prime}\right) d q .
\end{aligned}
$$

Note that

$$
\begin{aligned}
& {\left[v\left(q_{H}^{\prime \prime}\right)-\xi\left(q_{H}^{\prime \prime}\right)\right]-\left[v\left(q_{H}^{\prime}\right)-\xi\left(q_{H}^{\prime}\right)\right]-\int_{q_{H}^{\prime}}^{q_{H}^{\prime \prime}}\left(v^{\prime}(q)-\xi^{\prime}(q)\right) F^{n^{*}}\left(q \mid I^{\prime \prime}\right) d q } \\
= & -\left[1-F^{n^{*}}\left(q_{H}^{\prime} \mid I^{\prime \prime}\right)\right]\left[v\left(q_{H}^{\prime}\right)-\xi\left(q_{H}^{\prime}\right)\right]+\int_{q_{H}^{\prime}}^{q_{H}^{\prime \prime}}[v(q)-\xi(q)] d F^{n^{*}}\left(q \mid I^{\prime \prime}\right)>0,
\end{aligned}
$$

where the inequality follows from the fact that $v^{\prime}(q)-\xi^{\prime}(q)>0$ for $q>\hat{q}\left(<q_{H}^{\prime}\right)$. The term $[v(0)-\xi(0)]\left[F^{n^{*}}\left(q_{L} \mid I^{\prime \prime}\right)-F^{n^{*}}\left(q_{L} \mid I^{\prime}\right)\right]>0$ since $[v(0)-\xi(0)]>0$ and $F^{n^{*}}\left(q_{L} \mid I^{\prime \prime}\right)-$ $F^{n^{*}}\left(q_{L} \mid I^{\prime}\right)>0$. Finally, the term $-\int_{q_{L}}^{q_{H}^{\prime}}\left(v^{\prime}(q)-\xi^{\prime}(q)\right)\left[F^{n^{*}}\left(q \mid I^{\prime \prime}\right)-F^{n^{*}}\left(q \mid I^{\prime}\right)\right] d q>0$ since (1) for $q<\hat{q}, v^{\prime}(q)<\xi^{\prime}(q)$ and $F^{n^{*}}\left(q \mid I^{\prime \prime}\right)>F^{n^{*}}\left(q \mid I^{\prime}\right)$, and (2) for $q>\hat{q}, v^{\prime}(q)>\xi^{\prime}(q)$ and $F^{n^{*}}\left(q \mid I^{\prime \prime}\right)<F^{n^{*}}\left(q \mid I^{\prime}\right)$. This proves that $v_{I}^{*}\left(I^{\prime \prime}\right)-v_{I}^{*}\left(I^{\prime}\right)>E\left[\xi(q) \mid I^{\prime \prime}\right]-E\left[\xi(q) \mid I^{\prime}\right]>0$. Therefore, the equilibrium informed payoff $v_{I}^{*}(I)$ is increasing in $I$.

Proof of Proposition 5. A nondegenerate equilibrium satisfies $(16)$. Since $v_{I}^{*}(I)$ and $v_{U}^{*}(I)$ are continuous in $\left[I_{L}, I_{H}\right]$, so is $\Delta(I)$, which implies the existence of the extreme values $\Delta_{\min }$ and $\Delta_{\max } . \Delta_{\min }>0$ because $v^{\prime \prime}(q)>0$ and $n^{*} \geq 2$ for $I \in\left[I_{L}, I_{H}\right]$. Moreover, $\Delta_{\max }<v_{I}^{*}(M)<\infty$. Hence, for every $c \in\left[\Delta_{\min }, \Delta_{\max }\right]$, there exists $I^{*}$ such that $\Delta\left(I^{*}\right)=c$. For $c \notin\left[\Delta_{\min }, \Delta_{\max }\right]$, we have $\Delta\left(I^{*}\right) \neq c$ for all $I \in\left[I_{L}, I_{H}\right]$, which implies a degenerate equilibrium. 
Proof of Proposition 6. Implicitly differentiating $\Delta\left(I^{*}\right)=c, \frac{d I^{*}}{d c}=\frac{1}{d \Delta\left(I^{*}\right) / d I}$. Thus, $I^{*}$ is increasing in $c$ if and only if $\frac{d \Delta\left(I^{*}\right)}{\partial I}>0$. By definition,

$$
\frac{d \Delta(I)}{d I}=\frac{d v_{I}^{*}(I)}{d I}-\frac{d v_{U}^{*}}{d I}
$$

where $\frac{d v_{I}^{*}(I)}{d I}$ is given by $\mathrm{A}-13$ and

$$
\frac{d v_{U}^{*}}{d I}=\left(1+\left(q_{U}^{*}\right)^{r}\right)^{\frac{1}{r}-1}\left(q_{U}^{*}\right)^{r-1} \frac{d q_{U}^{*}}{d I} .
$$

Consider first $r$ arbitrarily close to 1 . Clearly, $\lim _{r \rightarrow 1} v\left(q_{L}\right)=1+q_{L}$ and $\lim _{r \rightarrow 1} v^{\prime}(q)=1$. By (A-13,

$$
\begin{aligned}
\lim _{r \rightarrow 1} \frac{d v_{I}^{*}(I)}{d I} & =\lim _{r \rightarrow 1}-q_{L} \frac{d F^{n^{*}}\left(q_{L}\right)}{d I}-\int_{q_{L}}^{q_{H}} \frac{d F^{n^{*}}(q)}{d I} d q \\
& =\lim _{r \rightarrow 1} \frac{d E\left[\widetilde{q}_{\max }^{*}\right]}{d I}
\end{aligned}
$$

and by $\mathrm{A}-15), \lim _{r \rightarrow 1} \frac{d v_{u}^{*}}{d I}=\lim _{r \rightarrow 1} \frac{d}{d I}\left(\frac{E\left[\widetilde{q}_{\max }^{*}\right]}{n^{*}}\right)$. Note that $\lim _{r \rightarrow 1} \Delta(I)=\frac{n^{*}-1}{n^{*}} E\left[\widetilde{q}_{\max }^{*}\right] \equiv$ $\Delta_{1}(I)$. Hence, $\lim _{r \rightarrow 1} \frac{d \Delta(I)}{d I}=\frac{d \Delta_{1}(I)}{d I}$.

First we show that there is a non-empty interval $I \in\left[I_{L}, \widetilde{I}\right]$ in which $\frac{d \Delta_{1}(I)}{d I}=\frac{\partial \Delta_{1}(I)}{\partial I}+$ $\frac{\partial \Delta_{1}(I)}{\partial n} \frac{\partial n^{*}(I)}{\partial I}>0$. Since $E\left[\widetilde{q}_{\max }^{*}\right]$ is increasing in $I$ (Lemma A2), $\frac{\partial \Delta_{1}(I)}{\partial I}>0$. Note that

$$
\begin{aligned}
\Delta_{1}(I) & =\frac{n^{*}-1}{n^{*}} \int_{q_{L}}^{q_{H}} n^{*} q f(q \mid r=1) F^{n^{*}-1}(q \mid r=1) d q \\
& =\int_{q_{L}}^{q_{H}} \frac{q}{(1+q)} F^{n^{*}}(q \mid r=1) d q
\end{aligned}
$$

where the second equality follows from the equilibrium pdf. Since $\frac{\partial F^{n^{*}}(q)}{\partial n^{*}}>0$ for $q<q_{H}$, $\frac{\partial \Delta_{1}(I)}{\partial n^{*}}>0$.

By Proposition 4, $n^{*}(I)$ is single-peaked, where $\frac{\partial n^{*}(I)}{\partial I}>0$ for some $I<I^{\prime}<I_{H}$. Therefore, by the continuity of $\Delta_{1}(I)$, there exists $\widetilde{I}$ such that $\Delta_{1}(I)$ is strictly increasing in $I$ for $I \leq \widetilde{I}$. As a result, for $c \in\left[\Delta_{\min }, \Delta(\widetilde{I})\right]$, there exists an equilibrium with $\frac{d I^{*}}{d c}=$ $\frac{1}{d \Delta\left(I^{*}\right) / d I}>0$. If $\widetilde{I}=I_{H}$, this nondegenerate equilibrium is unique for all $I \in\left[I_{L}, I_{H}\right]$ and $\widehat{\Delta}_{1}=\Delta\left(I_{H}\right)=\Delta_{\max }$.

Suppose $\widetilde{I}<I_{H}$ and let $\widehat{I}_{1}=\arg \min _{I \in\left(\widetilde{I}, I_{H}\right)} \Delta_{1}(I)$. We show that $\Delta_{1}\left(\widehat{I}_{1}\right)=\widehat{\Delta}_{1}>\Delta_{\text {min }}$, implying the uniqueness of the nondegenerate equilibrium for $c \in\left[\Delta_{\min }, \widehat{\Delta}_{1}\right)$. Recall that $n^{*}\left(I_{L}\right)=n^{*}\left(I_{H}\right)=2$ (see the proof of Proposition 2) and $n^{*}$ is single-peaked (Proposition 
4) reaching a maximum at $I^{\prime}<\widehat{I_{1}}$. Therefore, there exists $\underline{I} \in\left[I_{L}, I^{\prime}\right)$ such that $n^{*}(\underline{I})=$ $n^{*}\left(\widehat{I}_{1}\right)$. However, since $\frac{\partial \Delta_{1}(I)}{\partial I}>0$, we have $\widehat{\Delta}_{1}=\Delta_{1}\left(\widehat{I}_{1}\right)>\Delta_{1}(\underline{I}) \geq \Delta_{\text {min }}$. Therefore, for $c \in\left[\Delta_{\min }, \widehat{\Delta}_{1}\right)$, the nondegenerate equilibrium is unique. By the continuity of $\Delta(I)$ and $\frac{d \Delta(I)}{d I}$ in $r$, there is a unique nondegenerate equilibrium with $\frac{d I^{*}}{d c}>0$ as long as $r$ is sufficiently close to 1 and $c \in\left[\Delta_{\min }, \widehat{\Delta}\right)$ where $\widehat{\Delta}>\Delta_{\min }$.

Consider next $k$ arbitrarily close to 0 . We prove that $\lim _{k \rightarrow 0} \frac{d \Delta(I)}{d I}>0$ for all $I \in\left[I_{L}, I_{H}\right]$. By Proposition $3, \lim _{k \rightarrow 0} \frac{d \Delta(I)}{d I}=\lim _{n^{*} \rightarrow \infty} \frac{d \Delta(I)}{d I}$. We establish the latter by showing that $\lim _{n^{*} \rightarrow 0} \frac{d v_{I}^{*}}{d I}>0$ and $\lim _{n^{*} \rightarrow 0} \frac{d v_{U}^{*}}{d I}=0$.

From (A-15), $\lim _{n^{*} \rightarrow \infty} \frac{d v_{U}^{*}}{d I}=\lim _{n^{*} \rightarrow \infty}\left(1+\left(q_{U}^{*}\right)^{r}\right)^{\frac{1}{r}-1}\left(q_{U}^{*}\right)^{r-1} \frac{d q_{U}^{*}}{d I}$. Note that $\lim _{n^{*} \rightarrow \infty} q_{U}^{*}=$ 0 since $\lim _{n^{*} \rightarrow \infty} E\left[\widetilde{q}_{\text {max }}^{*}\right]<\infty$ (Proposition 3). We next show $\lim _{n^{*} \rightarrow \infty} \frac{d q_{u}^{*}}{d I}=0$. Note that

$$
\frac{d q_{U}^{*}}{d I}=\frac{1}{n^{*}}\left[\frac{\partial E\left[\widetilde{q}_{\max }^{*}\right]}{\partial I}-\frac{E\left[\widetilde{q}_{\max }^{*}\right]}{n^{*}} \frac{\partial n^{*}}{\partial I}\right]
$$

It is straightforward to verify that $\lim _{n^{*} \rightarrow \infty} \frac{\partial E\left[\tilde{q}_{\max }^{*}\right]}{\partial I} \stackrel{(? ? ?)}{=} \lim _{n^{*} \rightarrow \infty}-q_{L} \frac{\partial F^{n^{*}}\left(q_{L}\right)}{\partial I}-\int_{q_{L}}^{q_{H}}\left(\frac{\partial F^{n^{*}}(q)}{\partial I}\right) d q<$ $\infty$ since $\lim _{n^{*} \rightarrow \infty}-\frac{\partial F^{n^{*}}(q)}{\partial I}=\lim _{n^{*} \rightarrow \infty} \frac{n^{*}}{\left(n^{*}-1\right) I} F^{n^{*}}(q)=\frac{1+q^{r}}{q^{r-1} I}<\infty$. By implicit differentiation of $\mathrm{A}-4, \frac{d n^{*}}{d I}=-\frac{\partial h\left(n^{*} ; I\right) / \partial I}{\partial h\left(n^{*} ; I\right) / \partial n}$, where $\frac{\partial h\left(n^{*} ; I\right)}{\partial I}$ is given by $\mathrm{A}-6$ and

$$
\frac{\partial h\left(n^{*} ; I, r\right)}{\partial n}=\frac{M-I}{n^{*}} \frac{\left(q_{U}^{*}\right)^{r-1}}{\left(1+\left(q_{U}^{*}\right)^{r}\right)^{2}}\left[-\frac{q_{U}^{*}\left(1+\left(q_{U}^{*}\right)^{r}\right)}{n^{*}}+r \frac{\partial q_{U}^{*}}{\partial n}\right] .
$$

Using (A-7),

$$
\frac{\partial n^{*}}{\partial I}=-\frac{\frac{n^{*} r}{n^{*}-1} \frac{M-I}{I}\left[q_{H}-E\left[\widetilde{q}_{\max }^{*}\right]\right]-E\left[\widetilde{q}_{\max }^{*}\right]\left(1+\left(q_{U}^{*}\right)^{r}\right)}{(M-I)\left[-q_{U}^{*}\left(1+\left(q_{U}^{*}\right)^{r}\right)+r n^{*} \frac{\partial q_{U}^{*}}{\partial n}\right]} .
$$

Note that $\frac{\partial q_{U}^{*}}{\partial n}=-\frac{q_{U}^{*}}{n^{*}}+\frac{1}{n^{*}} \frac{\partial E\left[\widetilde{q}_{\max }^{*}\right]}{\partial n^{*}}$ and by Lemma A1, $\frac{\partial E\left[\tilde{q}_{\max }^{*}\right]}{\partial n^{*}}=q_{L} F^{n^{*}}\left(q_{L}\right) \frac{\ln F\left(q_{L}\right)}{\left(n^{*}-1\right)^{2}}+\int_{q_{L}}^{q_{H}} F^{n^{*}}(q) \frac{\ln F(q)}{\left(n^{*}-1\right)^{2}} d q$. Thus,

$$
\lim _{n^{*} \rightarrow \infty} \frac{E\left[\widetilde{q}_{\max }^{*}\right]}{n^{*}} \frac{\partial n^{*}}{\partial I}=-\frac{\frac{M-I}{I} r\left[q_{H}-\lim _{n^{*} \rightarrow \infty} E\left[\widetilde{q}_{\max }^{*}\right]\right]-\lim _{n^{*} \rightarrow \infty} E\left[\widetilde{q}_{\max }^{*}\right]}{(M-I)\left[-1+\lim _{n^{*} \rightarrow \infty} r \frac{\left(n^{*}\right)^{2}}{E\left[\widetilde{q}_{\max }^{*}\right]} \frac{\partial q_{U}^{*}}{\partial n}\right]} .
$$

By Proposition 3, $\lim _{n^{*} \rightarrow \infty} E\left[\widetilde{q}_{\max }^{*}\right]<\infty$. Substituting for $\frac{\partial q_{U}^{*}}{\partial n}$, we obtain $\lim _{n^{*} \rightarrow \infty} r \frac{\left(n^{*}\right)^{2}}{E\left[\tilde{q}_{\max }^{*}\right]} \frac{\partial q_{U}^{*}}{\partial n}=$ -1. This implies that $\lim _{n^{*} \rightarrow \infty} \frac{E\left[\tilde{q}_{\max }^{*}\right]}{n^{*}} \frac{\partial n^{*}}{\partial I} \in(-\infty, \infty)$, from which it is immediate that $\lim _{n^{*} \rightarrow \infty} \frac{d q_{U}^{*}}{d I}=0$ and $\lim _{n^{*} \rightarrow \infty} \frac{d v_{U}^{*}(I)}{d I}=0$.

It remains to show that $\frac{d v_{I}^{*}(I)}{d I}$ is strictly increasing in the limit, i.e., $\lim _{n^{*} \rightarrow \infty} \frac{d v_{I}^{*}(I)}{d I}>0$. By A-13), it is sufficient to show that $\lim _{n^{*} \rightarrow \infty} \frac{d F^{n^{*}}(q)}{d I}<0$ for all $q \geq q_{L}$ where $\frac{d F^{n^{*}}(q)}{d I}$ 
is given by $\mathrm{A}-14$. Note that the first term in $\mathrm{A}-14 \lim _{n^{*} \rightarrow \infty}-\frac{n^{*}}{n^{*}-1} \frac{F^{n^{*}}(q)}{I}=-\frac{1+q^{r}}{q^{r-1} I^{2}}<0$. Therefore, it is sufficient to show that the second term $\lim _{n^{*} \rightarrow \infty}-F^{n^{*}}(q) \ln \left(\frac{1+q^{r}}{q^{r-1} I}\right) \frac{1}{\left(n^{*}-1\right)^{2}} \frac{d n^{*}}{d I}=$ 0 . Given (A-17), it is straightforward to verify that $\lim _{n^{*} \rightarrow \infty} \frac{1}{\left(n^{*}-1\right)^{2}} \frac{d n^{*}}{d I}=0$, implying that $\lim _{n^{*} \rightarrow \infty} \frac{d F^{n^{*}}(q)}{d I}<0$ for all $q \geq q_{L}$ and $\lim _{n^{*} \rightarrow \infty} \frac{d v_{I}^{*}(I)}{d I}>0$. It follows that $\lim _{n^{*} \rightarrow \infty} \frac{d \Delta(I)}{d I}>0$ for all $I$. By continuity of $\frac{d \Delta(I)}{d I}$ with respect to $k$, it follows that for sufficiently small $k$, the value of information is increasing in $I$ for all $I \in\left[I_{L}, I_{H}\right]$. Setting $\widehat{\Delta}=\Delta_{\max }$, Proposition 6 obtains.

\section{Appendix B: Endogenous information with heterogenous costs}

In order to explain heterogeneity in donor information endogenously, we have assumed a homogenous information cost $c$ in Section 4. Here we demonstrate that a similar welfare result to Proposition 6 obtains under heterogeneous costs.

Suppose that each donor draws his information cost $c$ independently and privately from a continuous $\operatorname{cdf} G(c ; \alpha)$ with support $\left[c_{L}, c_{H}\right]$. Let $G_{\alpha}()<$.0 so that higher $\alpha$ implies a first-order stochastic increase in the information cost. As above a donor becomes informed in equilibrium if and only if $c \leq \Delta\left(I^{*}\right)$. Hence, the fraction of the informed is $G\left(\Delta\left(I^{*}\right) ; \alpha\right)$, which by definition equals $\frac{I^{*}}{M}$ whenever $I^{*} \in(0, M)$. Formally, in a nondegenerate equilibrium,

$$
G\left(\Delta\left(I^{*}\right) ; \alpha\right)-\frac{I^{*}}{M}=0 .
$$

Based on (17), let $\Delta_{\max }=\Delta\left(I_{\max }\right)$ and assume that $0 \leq c_{L}<c_{H} \leq \Delta_{\max }$. Since $v_{I}^{*}\left(I_{c}\right)=0$, we have $\Delta\left(I_{c}\right)=0$ and therefore $G\left(\Delta\left(I_{c}\right) ; \alpha\right)-\frac{I_{c}}{M}=-\frac{I_{c}}{M}<0$. Moreover, $G\left(\Delta_{\max } ; \alpha\right)-\frac{I_{\max }}{M}>0$. By the continuity of $\Delta(I)$, there exists a nondegenerate equilibrium with $I^{*} \in(0, M)$. It is unique if

$$
G^{\prime}(.) \Delta^{\prime}\left(I^{*}\right)-\frac{1}{M}>0 .
$$

Note that $\Delta^{\prime}\left(I^{*}\right)>0$ is necessary but not sufficient for the uniqueness. For the latter, we must have $\Delta^{\prime}\left(I^{*}\right)>G^{\prime}() /$.$M . In other words, under heterogenous costs, the non-$ degenerate equilibrium is unique if information acquisition decisions are strong strategic complements.

Suppose that (B-2) holds. Differentiating (B-1) with respect to $\alpha$, we find

$$
d I^{*} / d \alpha=-\frac{G_{\alpha}(.)}{G^{\prime}(.) \Delta^{\prime}\left(I^{*}\right)-\frac{1}{M}}>0
$$


Hence, if, as in Proposition 6, the nondegenerate equilibrium is unique, a stochastic increase in the information cost generates more informed giving. To understand its impact on social welfare, we write expected sum of donors' payoffs as

$$
W\left(I^{*}\right)=M\left[\int_{c_{L}}^{\Delta\left(I^{*}\right)}\left[v_{I}^{*}\left(I^{*}\right)-c\right] d G(c)+\int_{\Delta\left(I^{*}\right)}^{c_{H}} v_{U}^{*}\left(I^{*}\right) d G(c)\right] .
$$

Integrating by parts yields

$$
W\left(I^{*}\right)=M \int_{\mathcal{C}_{L}}^{\Delta\left(I^{*}\right)} G(c) d c+M v_{U}^{*}\left(I^{*}\right) .
$$

As a result, if, as in Proposition 6, the nondegenerate equilibrium is unique, a stochastic increase in the information cost implies a higher social welfare. 


\section{References}

[1] Aldashev, Gani, Marco Marini, and Thierry Verdier. "Brothers in alms? Coordination between nonprofits on markets for donations." Journal of Public Economics 117 (2014): 182-200.

[2] Andreoni, James. "Impure altruism and donations to public goods: a theory of warmglow giving." Economic Journal (1990): 464-477.

[3] Andreoni, James. "Leadership giving in charitable fund-raising". Journal of Public Economic Theory 8 (2006), 1-22.

[4] Andreoni, James, and A. Abigail Payne. Charitable giving. Handbook of Public Economics 5 (2013): 1-50.

[5] Andreoni, James, and John Miller. "Giving according to GARP: An experimental test of the consistency of preferences for altruism." Econometrica 70, no. 2 (2002): 737-753.

[6] Bilodeau, Marc, and Al Slivinski. "Rival charities." Journal of Public Economics 66(3) (1997): 449-467.

[7] Castaneda, Marco A., John Garen, and Jeremy Thornton. "Competition, contractibility, and the market for donors to nonprofits." Journal of Law, Economics, and Organization 24(1) (2008): 215-246.

[8] Che, Yeon-Koo, and Ian Gale. "Optimal design of research contests." American Economic Review 93(3) (2003): 646-671.

[9] Eckel, Catherine C., and Philip J. Grossman. "Altruism in anonymous dictator games." Games and Economic Behavior 16(2) (1996): 181-191.

[10] Fisman, Raymond, Shachar Kariv, and Daniel Markovits. "Individual preferences for giving." American Economic Review 97, no. 5 (2007): 1858-1876.

[11] Fong, Christina M., and Felix Oberholzer-Gee. "Truth in giving: Experimental evidence on the welfare effects of informed giving to the poor." Journal of Public Economics 95(5) (2011): 436-444.

[12] Glazer, Amihai, and Kai A. Konrad. "A signaling explanation for charity." American Economic Review (1996): 1019-1028. 
[13] Gneezy, Uri, Elizabeth A. Keenan, and Ayelet Gneezy. "Avoiding overhead aversion in charity." Science 346.6209 (2014): 632-635.

[14] Krasteva, Silvana, and Huseyin Yildirim. "(Un) Informed charitable giving." Journal of Public Economics 106 (2013): 14-26.

[15] Morgan, John, and Felix Várdy. "The value of commitment in contests and tournaments when observation is costly." Games and Economic Behavior 60.2 (2007): 326-338.

[16] Reich, Rob, Lacey Dorn, and Stefanie Sutton. "Anything goes: Approval of nonprofit status by the IRS." Stanford, CA: Stanford University Center on Philanthropy and Civil Society. (2009).

[17] Rose-Ackerman, Susan. "Charitable giving and "excessive" fundraising." The Quarterly Journal of Economics (1982): 193-212.

[18] Scharf, Kimberley. "Impure prosocial motivation in charity provision: Warm-glow charities and implications for public funding." Journal of Public Economics 114 (2014): 50-57.

[19] Siegel, Ron. "Asymmetric contests with conditional investments." American Economic Review 100(5) (2010): 2230-2260.

[20] Steinberg, Richard. "Does government spending crowd out donations? Interpreting the evidence," Annals of Public and Cooperative Economics 1991: 591-617.

[21] Urban Institute, National Center for Charitable Statistics Annual Report, 2014.

[22] Varian, Hal R. “A model of sales." American Economic Review (1980): 651-659.

[23] Vesterlund, Lise. "The informational value of sequential fundraising," Journal of Public Economics 87 (2003), 627-57.

[24] Yildirim, Huseyin. "Andreoni-McGuire algorithm and the limits of warm-glow giving." Journal of Public Economics 114 (2014): 101-107.

[25] Yoruk, Baris. "Charity ratings," Journal of Economics and Management Strategy, Forthcoming. 